\title{
Block and Graft Copolymerization by Controlled/Living Radical Polymerization Methods
}

Hülya Arslan

Additional information is available at the end of the chapter

http://dx.doi.org/10.5772/45970

\section{Introduction}

Copolymerization is a versatile synthetic tool for controlling the functionality and, therefore, tailoring of the physical and mechanical properties of macromolecules. Block copolymers are one of the most important polymeric materials in technological applications and theoretical research because of their exceptional properties due to the microphase separation [1]. Many basic characteristics of block copolymers and graft copolymers are similar. Graft copolymers also exhibit good phase separation and are used for a variety of applications, such as impact-resistant plastics, thermoplastic elastomers, compatibilizers and polymeric emulsifers. Because of their branched structure they generally have also lower melt viscosities, which is advantageous for processing. They have great potential to realize new properties because of their structural variables (composition, backbone length, branch length, branch spacing, etc.) [2,3]. Various polymerization methods have been used to synthesis block and graft copolymers, such as free radical, anionic, cationic, coordination, group transfer, coupling, changing polymerization mechanism, step growth, macroinitiators, metathesis and many books [4,5], chapters of encyclopaedia [6-10], papers [11,12] offer excellent reviews of research on synthesis block and graft copolymers by these methods.

According to literature, the most common and widely used approach is free-radical polymerization method. Free-radical polymerization is particularly interesting because of its adaptability to a wide range of functinal monomers under less stringent synthesis conditions. Unfortunately, uncontrolled nature of conventinal free-radical polymerization leads to homopolymerzation during the polymerization resulting in a product that is a mixture of homopolymer and copolymer. A major drawback of conventional radical polymerization is that almost no control over the molecular weight, molecular weight 
distribution and architecture of the polymer is possible, making its macroscopic properties very difficult to be tailored. Living ionic polymerizations can provide a methodology for preparation of copolymers with well-defined structures, such as controlled molecular weights and narrow molecular weight distribution, defined copolymer compositions, branching and end-group functionalities. There are various drawbacks that often retard the practical application of living ionic systems to prepare copolymers. These drawbacks are limitation of the method to certain monomers and their sensitivity to moisture, carbon dioxide, and numerous other acidic or basic compounds.

Polymer chemists have long tried to combine the advantages of both radical and ionic polymerizations in a single polymerizations process. These attempts have been principally successful by controlled/living radical polymerization (CRP) techniques. Controlled/living radical polymerization in brief is based on an understanding and integration of chemistry developed over 60 years in the fields of organic chemistry, conventional radical polymerization and living ionic polymerizations. Recently, extensive research has been carried out in the field of controlled/living radical polymerization (CRP), because it can be employed for the polymerization of numerous vinyl monomers under mild reaction conditions and these methods enable the synthesis of well-defined polymer structures with controlled molecular weight and narrow molecular weight distribution. CRP includes atom transfer radical polymerization (ATRP), nitroxide-mediated polymerization (NMP), and reversible addition-fragmentation chain transfer (RAFT) polymerization. Each of these methods relies on establishment of a rapid dynamic equilibrium between a low concentration of active propagating chains and a predominant amount of dormant chains that are unable to propagate or terminate, and is more tolerant towards functional groups and impurities. Recently, many studies have been reported in the literature about the synthesis of macromolecules with various compositions (homopolymers, random, periodic, block, graft and gradient copolymers) and novel topologies (linear, star, comb, branched, hyper branched, networks, brushes etc.) using CRP techniques [13-30]. It is observed that the significant improvement in block and graft copolymer synthesis has become with development of controlled/living radical polymerization (CRP) techniques. This chapter focuses on the preparation of block and graft copolymers via controlled/living radical polymerization (CRP) techniques which are new and efficient synthetic strategies.

\section{Controlled/living radical polymerization (CRP)}

CRP can be described as "A radical polymerization that can be stopped and re-initiated under external control" and shown schematically in Figure 1.

General CRP mechanism can be summarized as follows;

Dormant species

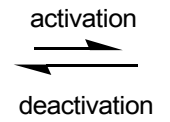

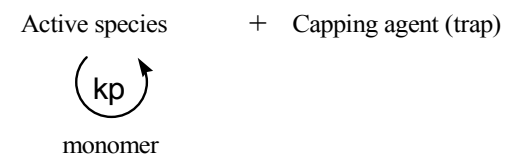




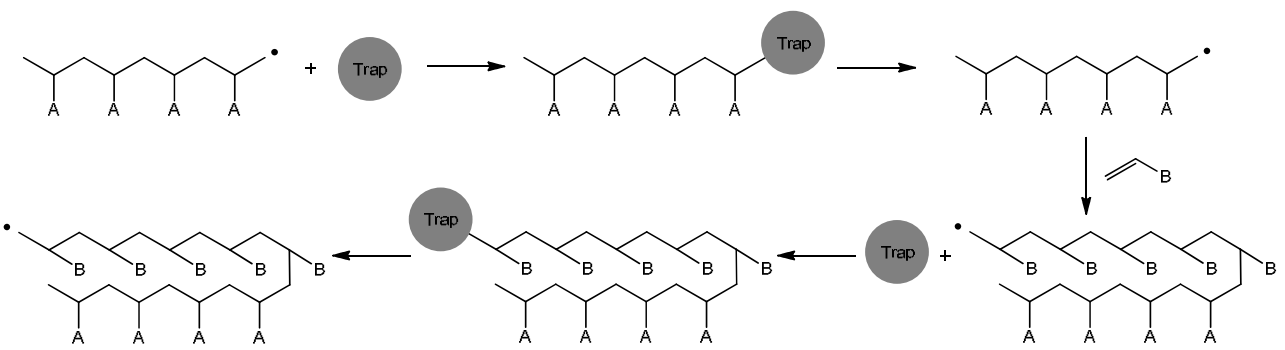

Figure 1. Schematic representation of $C R P$

Equilibrium is established between dormant, end-capped chains, unable to propagate or terminate, and the active species. The equilibrium should be shifted towards the dormant species and exchange between active and dormant species should be fast relative to propagation. CRP distinguishes itself from conventional radical polymerization by involving a reversible activation process.

\subsection{Historical evolution of CRP}

Table 1 illustrate development of fundamental concepts in organic radical processes, some concepts in living ionic polymerization and advances in radical polymerizations which all have contributed to controlled/ "living" radical polymerization. The success of controlled/ "living" radical polymerization is an integration of advances in synthetic organic chemistry, living ionic polymerization and conventional radical polymerization (Figure 2) [31,32].

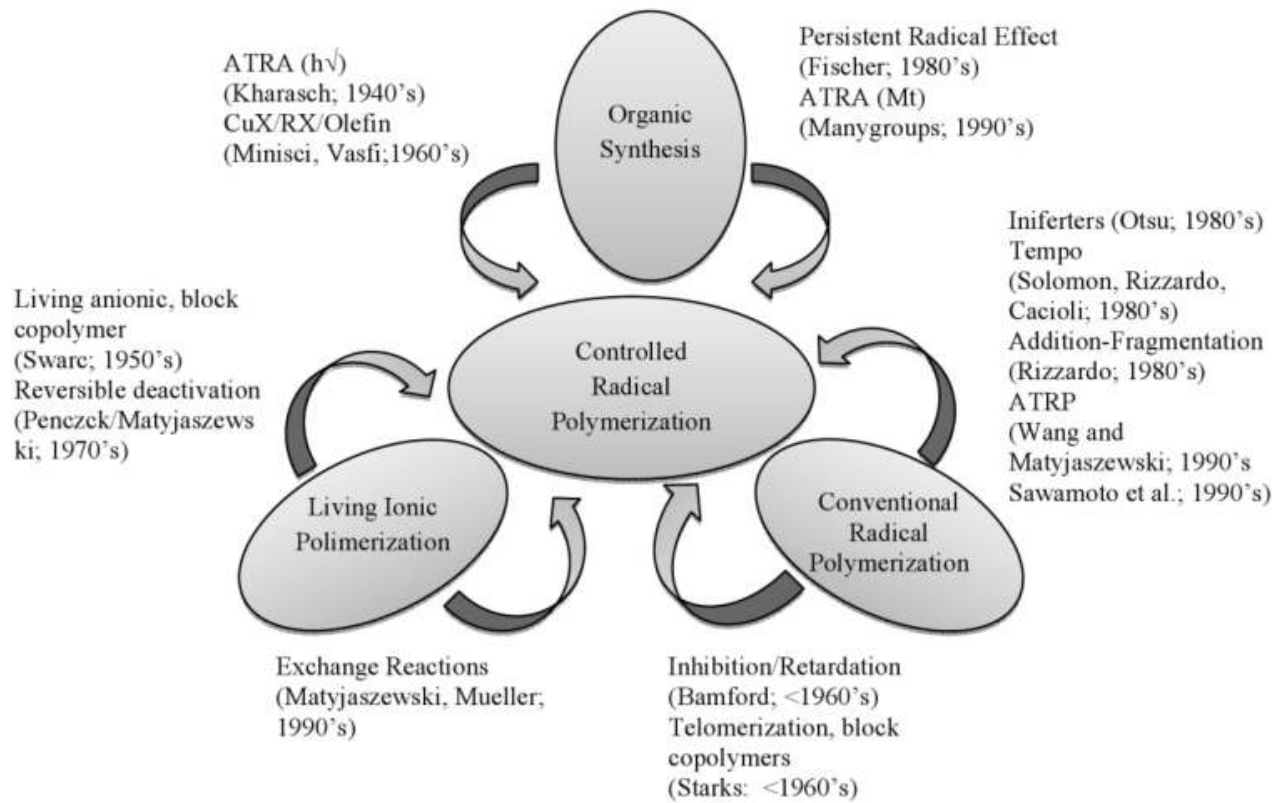

Figure 2. Development of CRP by integration of advances in several fields of chemistry 


\begin{tabular}{|c|c|c|c|}
\hline c synthesis & $\begin{array}{l}\text { Living ionic } \\
\text { polymerization }\end{array}$ & $\begin{array}{l}\text { Conventional radical } \\
\text { polymerization }\end{array}$ & $\begin{array}{l}\text { Controlled/ } \\
\text { "living" radical } \\
\text { polymerization }\end{array}$ \\
\hline $\begin{array}{l}\text { 1940s } \\
\text { Kharash: First ATRA } \\
\text { (hv) } \\
\text { 1960s } \\
\text { Minisci, Vosfi: } \\
\text { CuX/RX/Olefin } \\
\text { Rosantsev: Nitroxide } \\
\text { Kochi: Free radicals\&Mt } \\
\text { 1980s } \\
\text { Fischer: Persistent } \\
\text { Radical Effect (PRE) } \\
\text { 1990s } \\
\text { Many groups: ATRA } \\
\text { (Mt) }\end{array}$ & $\begin{array}{l}\text { 1950s } \\
\text { Szwarc: Living anionic } \\
\text { polym., block } \\
\text { copolymers } \\
\text { 1970s } \\
\text { Penczek/Matyjaszewski: } \\
\text { Reversible deactivation } \\
\text { in Cationic Ring } \\
\text { Opening } \\
\text { Polymerization (CROP) } \\
\text { 1980s } \\
\text { Kennedy: Inifers, } \\
\text { Kennedy, Higashimura, } \\
\text { Sawamoto, Sigwalt, } \\
\text { Matyjaszewski: } \\
\text { Carbocationic } \\
\text { 1990s } \\
\text { Matyjaszewski, Mueller: } \\
\text { Exchange reactions }\end{array}$ & $\begin{array}{l}<1960 \text { s } \\
\text { Bambord: } \\
\text { Inhibition/retardation } \\
\text { Starks: Telomerization, } \\
\text { block copolymers } \\
\text { 1970s } \\
\text { Minoura: } \\
\text { Cr(II)acetate/MMA } \\
\text { 1980s } \\
\text { Otsu: “1st” Living radical } \\
\text { polym., Iniferters } \\
\text { Solomon, Rizzardo, Cacioli: } \\
\text { Stable Free Radical } \\
\text { Polymerization (SFRP)- } \\
\text { Synthesis of oligomers with } \\
\text { nitroxide (TEMPO) } \\
\text { Rizzardo: Addition- } \\
\text { fragmentation (RAFT) } \\
\text { 1990s } \\
\text { Georges: TEMPO mediated } \\
\text { styrene polym. (NMP) } \\
\text { Wang and Matyjaszewski: } \\
\text { ATRP } \\
\text { Sawamoto: ATRP }\end{array}$ & $\begin{array}{l}\text { 1980s } \\
\text { Otsu: Iniferters } \\
\text { Solomon, Rizzardo, } \\
\text { Cacioli: (SFRP)- } \\
\text { (TEMPO) } \\
\text { Rizzardo: (RAFT) } \\
\text { 1990s } \\
\text { Georges: } \\
\text { TEMPO/styrene } \\
\text { (NMP) } \\
\text { Wang and } \\
\text { Matyjaszewski: } \\
\text { ATRP } \\
\text { Sawamoto: ATRP }\end{array}$ \\
\hline
\end{tabular}

Table 1. Evolution of controlled/ "living" Radical Polymerization [31,32]

Radical addition reactions have for a long time been considered to be very difficult to control due to termination reactions which not be avoided. Probably the first example of a successful addition of halogenated compounds to alkenes via radical intermediates (atom Transfer Radical Addition, ATRA) was provided by Kharash under photochemical conditions. This atom transfer radical process was subsequently converted to metal catalyzed reactions by Minisci, Vosfi and others during the 1960s.

In 1982 Otsu et al., for the first time, used the term living radical polymerization to describe a free radical polymerization in the presence of dithiocarbamates. In analogy to the inifer used in carbocationic systems, they proposed that dithiocarbamates acts as iniferters, i.e. agents which initiate, transfer and terminate. Unfortunately, as in the previously discussed systems, polydispersities were always relatively high, molecular weights did not evolve linearly with conversion and initiation efficiency was low. A new system for controlling radical polymerization based on nitroxides as stable free radicals is developed by Solomon, Rizzardo and Cacioli in 1986. They synthesized methyl acrylate oligomers via reversible 
capping of growing radical chain by using 2,2,6,6-tetramethyl-1-piperidinyloxy (TEMPO) as a stable free radical. The reversible capping of growing chains defined the first mechanism of three general routes to controlled/ "living" radical polymerization. This route was named as "Stable Free Radical Polymerization (SFRP)" by its discovers. Three main types of techniques have been developed over the years: 1) stable free radical polymerization (SFRP) with nitroxide-mediated radical polymerization (NMP), 2) atom transfer radical polymerization (ATRP) and 3) reversible addition-fragmentation transfer polymerization (RAFT).

\subsection{Equilibrium (reversible activation/deactivation) for the three major CRP processes}

The reversible activation/deactivation reactions (dynamic equilibrium) in the most effective CRP process may be classified mechanistically into three types, which are (a) dissociationcombination (DC) (coupling), (b) atom transfer (AT) and (c) degenerative chain transfer (DT).

(a) Reversible deactivation by dissociation-combination (coupling). e.g. Nitroxide-mediated polymerization (NMP)

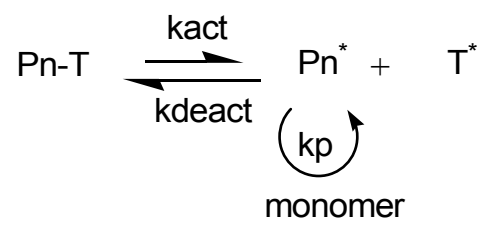

(b) Reversible deactivation by atom transfer. e.g. ATRP

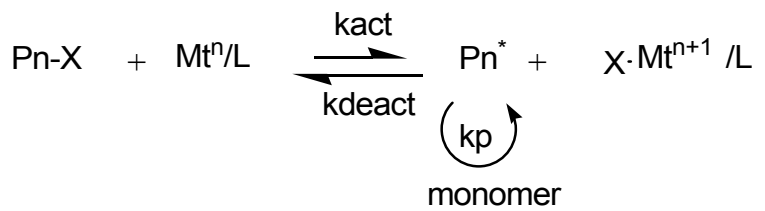

(c) Degenerative chain transfer. e.g. RAFT

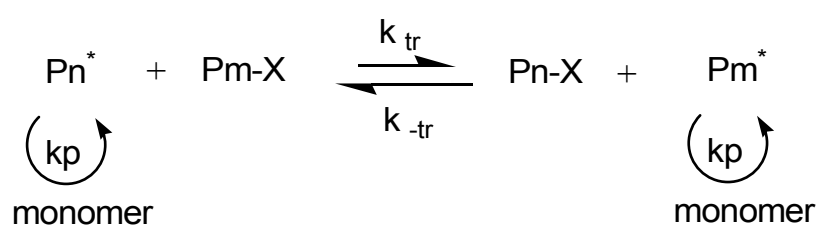

Each of these methods relies on establishment of a dynamic equilibrium between a low concentration of active propagating chains and a predominant amount of dormant chains 
that are unable to propagate or terminate as a means of extending the lifetime of the propagating chains.

\subsection{General features of CRP}

It is widely accepted that a controlled polymerization process should display the following features:

1. First-order Kinetic Behavior

2. Pre-determinable Degree of Polymerization

3. Designed (Usually) Narrow Molecular Weight Distribution

4. Long-lived Polymer Chain with Preserved End Functionalities

\subsubsection{First-order kinetic behavior:}

The polymerization rate $\left(R_{\mathrm{p}}\right)$ with respect to the log of the monomer concentration $([\mathrm{M}])$ is a linear function of time. This is due to the negligible contribution of non-reversible termination, so that the concentration of the active propagating species $\left(\left[\mathrm{P}^{*}\right]\right)$ is constant.

$$
\begin{gathered}
\mathrm{R}_{\mathrm{p}}=\frac{-d[M]}{d t}=k_{p}\left[P^{*}\right][M] \\
\ln \frac{[M]_{0}}{[M]}=k_{p}\left[P^{*}\right] \mathrm{t}=k_{p}^{a p p} \mathrm{t} \text { (if }\left[\mathrm{P}^{*}\right] \text { is constant) }
\end{gathered}
$$

$\mathrm{k}_{\mathrm{p}}$ is the propagation constant. The consequence of equation (6) and the effect of changes in $\mathrm{P}^{*}$ are illustrated in below:

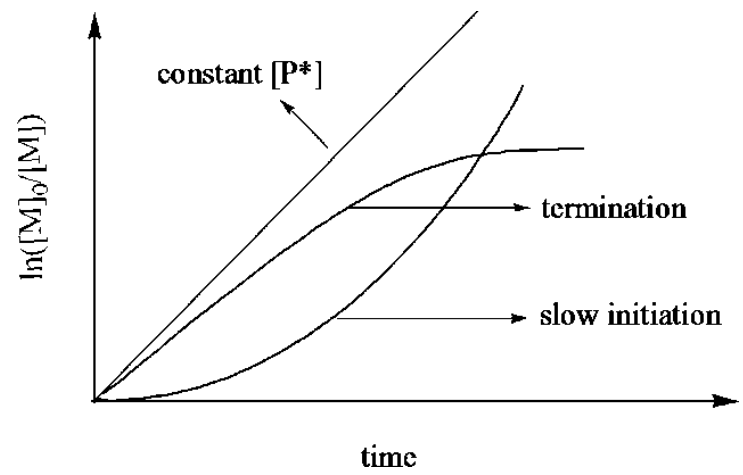

Figure 3. Illustration of the dependence of $\ln ([\mathrm{M}] \mathrm{o} /[\mathrm{M}])$ on time

This semi logarithmic plot is very sensitive to any change of the concentration of the active propagating species. A constant $\left[\mathrm{P}^{*}\right]$ is revealed by a straight line. A steady $\left[\mathrm{P}^{*}\right]$ in a CRP is established by balancing the rates of activation and deactivation and not by balancing the rates of initiation and termination as in a conventional radical polymerization. An upward curvature 
in the kinetic plot indicates an increase in $\left[\mathrm{P}^{*}\right]$, which occurs in case of slow initiation. On the other hand, a downward curvature suggests a decrease in $\left[\mathrm{P}^{*}\right]$, which may result from termination reactions increasing the concentration of the persistent radical, or some other side reactions such as the catalytic system being poisoned or redox processes on the radical.

It should also be noted that the semi logarithmic plot is not sensitive to chain transfer processes or slow exchange between different active species, since they do not affect the number of the active propagating species.

\subsubsection{Pre-determinable degree of polymerization:}

Degree of polymerization (DPn), i.e. the number average molecular weight $\left(\mathrm{Mn}_{\mathrm{n}}\right)$ is a linear function of monomer conversion.

$$
D P_{n}=\frac{\mathrm{M}_{n}}{\mathrm{M}_{0}}=\frac{\Delta[\mathrm{M}]}{[\mathrm{I}]_{0}}=\frac{[\mathrm{M}]_{0}}{[\mathrm{I}]_{0}}(\text { conversion })
$$

This result comes from maintaining a constant number of chains throughout the polymerization, which requires the following two conditions:

1. initiation should be sufficiently fast so that essentially all chains are propagating before the reaction is stopped; and

2. an absence of chain transfer reactions that increases the total number of chains.

Figure 4 illustrates feature 2 and shows the ideal growth of molecular weight with conversion, as well as the effects of slow initiation and chain transfer on the molecular weight evolution.

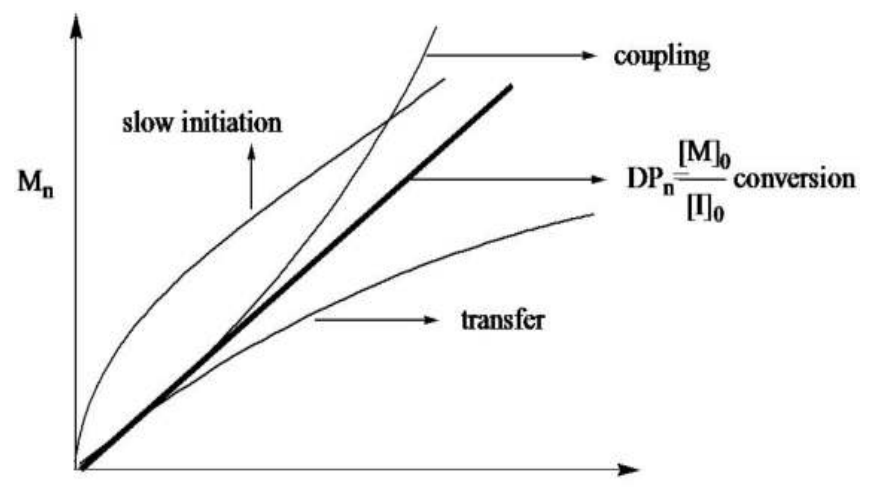

Conversion

Figure 4. Illustration of the dependency of molecular weight on conversion

It is important to recognize that the evolution of molecular weight is not very sensitive to chain termination, since the number of chains remains unchanged. The effect of termination is only observable on the plot when coupling reactions, forming higher molecular weight polymers, start to play a significant role. 


\subsubsection{Designed, usually narrow, molecular weight distribution:}

Although this feature is often desirable, it is not necessarily the result of a controlled polymerization, which only requires the absence of chain transfer and termination, but ignores the effect of rate of initiation, exchange and depropagation.

In order to obtain a polymer with a narrow molecular weight distribution, each of the following requirements should be fulfilled.

i. The rate of initiation is fast in comparison to the rate of propagation. This condition allows simultaneous growth of all the polymer chains.

ii. The exchange between species of different reactivity is fast in comparison with the rate of propagation. This condition ensures that all the active chain termini are equally susceptible to reaction with monomer allowing uniform chain growth.

iii. There must be negligible chain transfer or termination.

iv. The rate of depropagation is substantially lower than propagation. This guarantees that polymerization is essentially irreversible.

This should yield a Poisson distribution, as quantified in equation (8).

$$
\frac{X_{w}}{X_{n}}=\frac{M_{w}}{M_{n}}=1+\frac{X_{n}}{\left(X_{n}+1\right)^{2}} \cong 1+\frac{1}{X_{n}}
$$

According to equation (8), polydispersity (PDI $=M_{w} / M_{n}$ ) decreases with increasing molecular weight.

\subsubsection{Long-lived polymer chains with preserved end-functionalities:}

This is a consequence of negligible irreversible chain transfer and termination. Hence, all the chains retain their active centers after the full consumption of the monomer. Propagation resumes upon introduction of additional monomer. This unique feature enables the preparation of block copolymers by sequential monomer addition. The significance of controlled polymerization as a synthetic tool is widely recognized and polymers having uniform predictable chain length are readily available. Controlled polymerization provides the best opportunity to control the bulk properties of target materials through control of the multitude of possible variations in composition, functionality and topology now attainable at a molecular level. Through appropriate selection of the functional (macro) initiator, copolymers formed in a controlled/"living" polymerization process can have essentially any desired topology. Further, the nature of the mechanism enables specific end functionalization and addition of a second monomer to make a block copolymer.

\subsection{Potential applications of CRP processes}

The development of CRP has allowed the preparation of many new materials with vastly differing properties simply by varying the topology of the polymer (i.e., comb, star, 
dendritic, etc.), the composition of the polymer (i.e., random, periodic, graft, etc.), or the functional groups at various sites on the polymer (i.e., end, center, side, etc.) (Figure 5) [33].

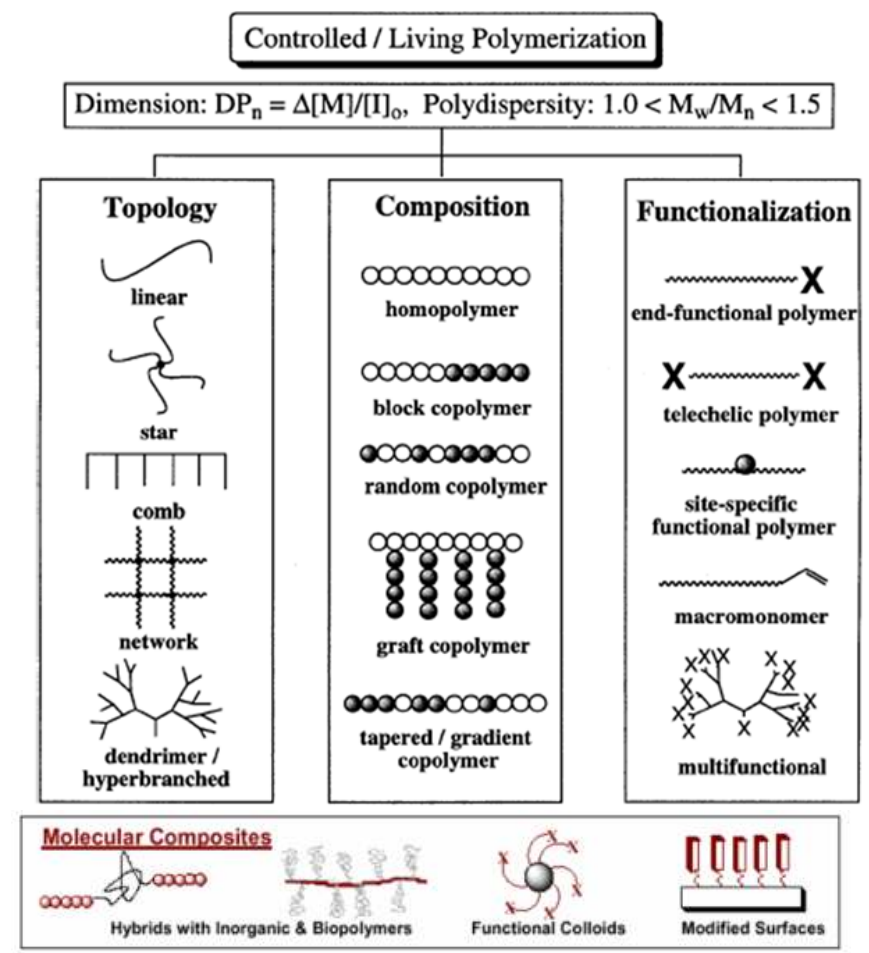

Figure 5. A schematic representation of how new polymers and materials can be prepared using controlled/living radical polymerizations

\section{Blok copolymerization}

Polymers which are composed of two different monomers are usually referred to as copolymers. The sequential arrangement of these different monomers determines the type of copolymer that is formed. In the case of a random distribution of the two monomer over the polymer chain, the product is called a random copolymer. In a linear block copolymer, the monomeric residues are arranged in such a way that one block consists of monomeric residue $\mathrm{A}$ and another block of monomeric residue $\mathrm{B}$. Block copolymers are defined as having a linear arrangement of blocks of varying monomer composition. That is, a block copolymer is a combination of two or more polymers joined end-to-end. Moreover, one can synthesize more exotic structures such as four- or six-arm starblock copolymers and comblike block copolymers. These have branched structures.

The increasing importance and interest in block copolymers arises mainly from their unique properties in solution and in the solid state which are a consequence of their molecular 
structure. In particular, sequences of different chemical composition are usually incompatible and therefore have a tendency to segregate in space. Amphiphilic properties in solution and microdomain formation in solid state are directly related to this specific molecular architecture, which can be designed by using existing monomers or polymers. Block copolymers are generally applied as adhesives (e.g. surfactants and viscosity improvers), compatibilizers, thermoplastic elastomers, etc.

The concept of block copolymer synthesis started in 1956 when Szwarc discovered living anionic polymerization. A living process implies that all polymer chains start growing simultaneously; while during chain growth no termination or chain transfer takes place. Consequently, all chains grow for a similar period, and a narrow molecular weight distribution is obtained. When all monomer has been consumed, the active center persists, and upon addition of a new batch of monomer, polymerization continues to form a block copolymer. Anionic polymerization however requires very stringent reaction conditions, as the carbon-centered anion is very sensitive to traces of impurities. Industrially, anionic polymerization is therefore not frequently used. Later, block copolymer synthesis was also achieved by other living polymerization techniques, such as ring opening polymerization and cationic polymerization or by pseudo-living techniques like Ziegler-Natta catalysis. These polymerization techniques, however, suffer from a number of disadvantages: most of them do not tolerate even extremely low levels of impurities (like e.g. moisture or oxygen), and are compatible only with a limited number of monomers. Also these processes are very expensive, due to the special equipment and the reaction conditions that are needed to perform these reactions. This obviously leads to an expensive polymer product. An entirely different synthetic concept towards (multi)block copolymers makes use of the polycondensation principle. Since the early 1980s, there were several early attempts to synthesize block copolymers via regulated free-radical polymerizations. These methods utilized so-called iniferters, i.e. compounds which could serve as INItiators, transFER agents and TERminating agents. However, while useful, these techniques did not offer the desired level of control over macromolecular structure, due to poor molecular weight control, high polydispersities, and low blocking efficiency. This was attributed to slow initiation, slow exchange, direct reaction of counter radicals with monomers, and thermal decomposition of the iniferter. In the last decade, some polymerization techniques that combine the versatility of free radical polymerization with the control of anionic polymerization emerged. These techniques are referred to as controlled radical polymerizations, such as Nitroxide-Mediated Polymerization (NMP), Atom Transfer Radical Polymerization (ATRP) and Reversible Addition-Fragmentation chain Transfer (RAFT) and are based on two principles: reversible termination and reversible transfer. These techniques have enabled researchers to synthesize block copolymers under less stringent conditions than those necessary for living ionic polymerizations: it is possible to work under similar conditions as used in free-radical polymerizations. The synthesis of block copolymers by general polymerization methods such as free radical, anionic, cationic, coordination, coupling, step growth, ring opening, changing polymerization mechanism (active centers transformation reactions), have summarized several times in the literature [1,4,6-10,34]. In this chapter we will focuses on the preparation of block and graft copolymers via controlled/living radical polymerization (CRP) techniques which are new and efficient synthetic strategies. 
Block copolymers can be prepared by controlled polymerization routes in two strategies which are the sequential monomer addition strategy and the use of a difunctional initiator. In the sequential monomer addition strategy, certain experimental conditions governing the growth of the first block should be handled carefully to increase the blocking efficiency. It is essentially important to stop the polymerization of the first monomer before it is used up completely for the fact that end functionalities might be lost, resulting in the formation of dead blocks. Another feature to be considered, as in all sequential monomer additions, is the order of introducing each monomer [35]. In brief, the very active monomer should be polymerized first, which is valid for either of the controlled polymerization mechanisms. Different from sequential monomer addition technique utilized in anionic living polymerization, controlled routes allow for the polymerization of monomers A and B to be performed separately in two distinct steps, allowing chain functionalities to be preserved. The first block functions as a macromolecular initiator, a so-called macroinitiator, in the preparation of the second block.

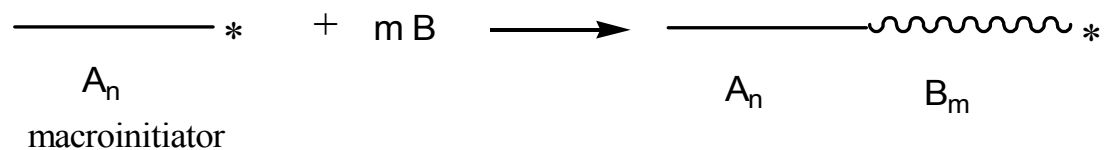

By this way $\mathrm{AB}$ type diblock copolymers can be prepared. Further, the nature of the mechanism of CRP enables specific end functionalization and addition of a another monomer $(\mathrm{C})$ to make $\mathrm{ABC}$ type triblock copolymer:

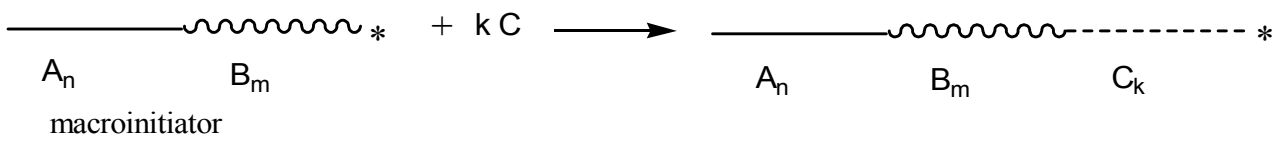

Another route involves the use of a difunctional initiator and has been employed in the preparation of ABA type symmetric triblock copolymers. In this methodology, a compound possessing two initiating sites is utilized in the formation of the middle block first, followed by the polymerization of the second monomer to synthesize the first and the third blocks. This allows the preparation of the ABA type triblock copolymer in two steps, instead of three steps:
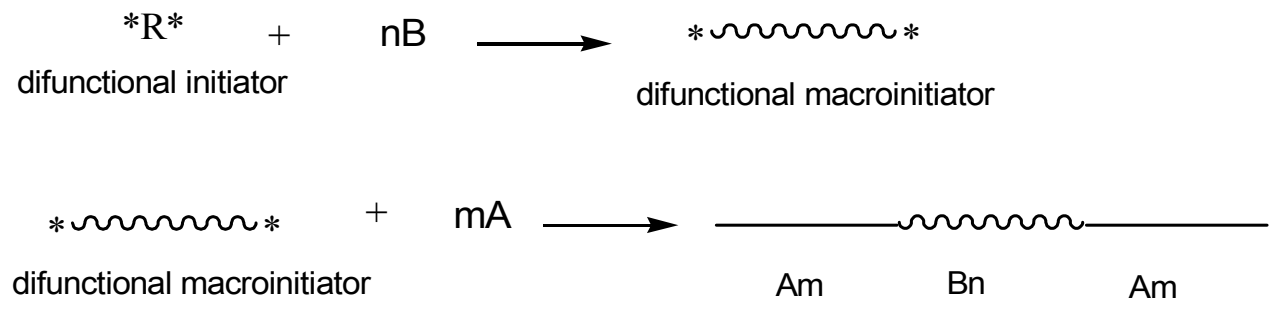


\subsection{Block copolymerization via Nitroxide Mediated Radical Polymerization (NMP)}

Two basic strategies have been applied to initiate NMP. The first method involves use of a conventional initiator (e.g. AIBN, BPO) in the presence of a nitroxide and this system is called as "bimolecular NMP" (Scheme 1).
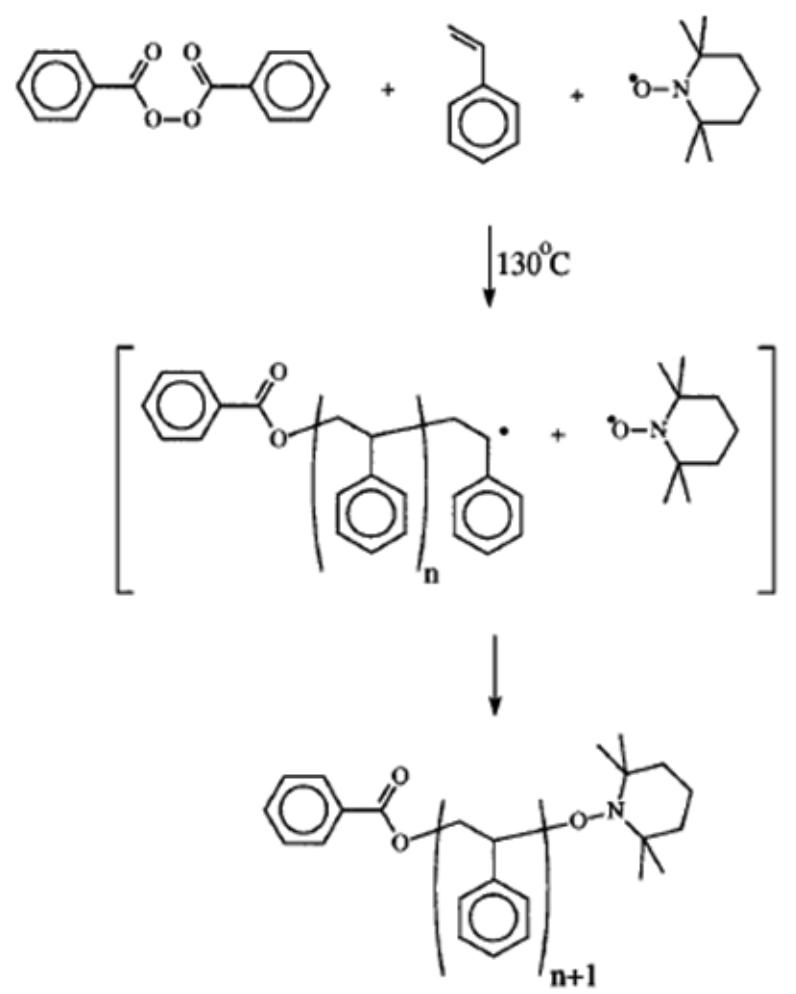

Scheme 1. Bimolecular initiation in NMP

The second method is called as "unimolecular NMP" (Scheme 2) and it is possible when the initiator is a low molecular weight alkoxyamine. In this system the free radical initiator is not required and the $\mathrm{C}-\mathrm{O}$ bond of the small molecule alkoxyamine derivative is therefore expected to be thermolytically unstable and decompose on heating to give an initiating radical [27].

Bosman et al. reported the preparation of poly(ethylene glycol)-based block copolymers by initial reaction of mono-hydroxy terminated poly(ethylene glycol) with sodium hydride followed by the chloromethyl-substituted alkoxyamine. The PEG-based macroinitiator is used in the nitroxide mediated radical polymerization of styrene to give amphiphilic block copolymer (Scheme 3) [36]. 
<smiles>CC(ON1C(C)(C)CCCC1(C)C)c1ccccc1</smiles>

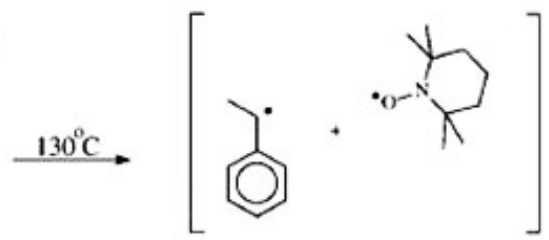<smiles>Cc1ccccc1C=Cc1ccccc1</smiles><smiles>CC(C)c1ccccc1CC(C)(ON1C(C)(C)CCCC1(C)C)c1ccccc1</smiles>

Scheme 2. Unimolecular initiation in NMP

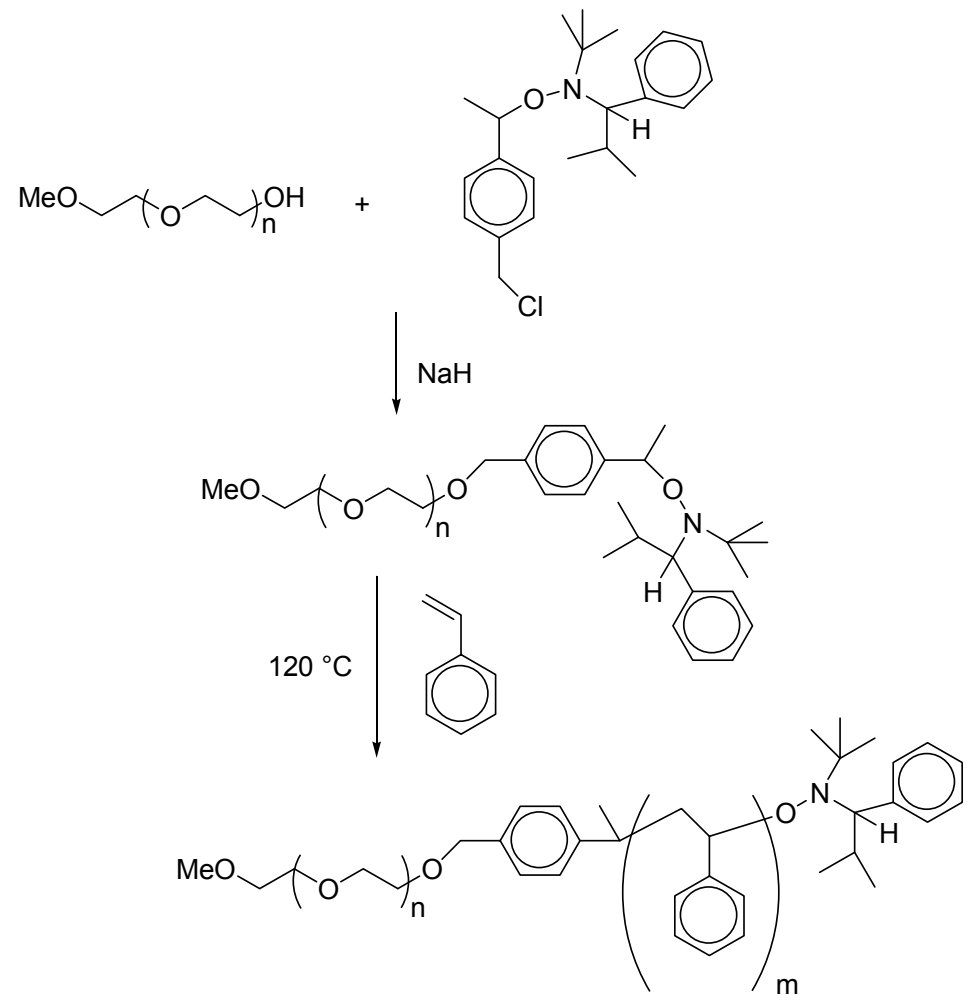

Scheme 3. The synthesis of PEG- $b$-PS by NMP 
Choi et al. reported the preparation of functional segmented block copolymers containing localized pyrene groups through convenient NMP processes for the versatile nondestructive functionalization of carbon nanotubes (CTAs). Polystyrene was employed as an organic tail to improve the solubility and dispersibility of CTA in organic mediums and polystyrene compatible polymer matrices (Scheme 4) [37].<smiles>[Z20]C1(C)CCCC(C)(C)N1O[C@H]1CC[C@H](O[Na])[C@H]1C=C</smiles>

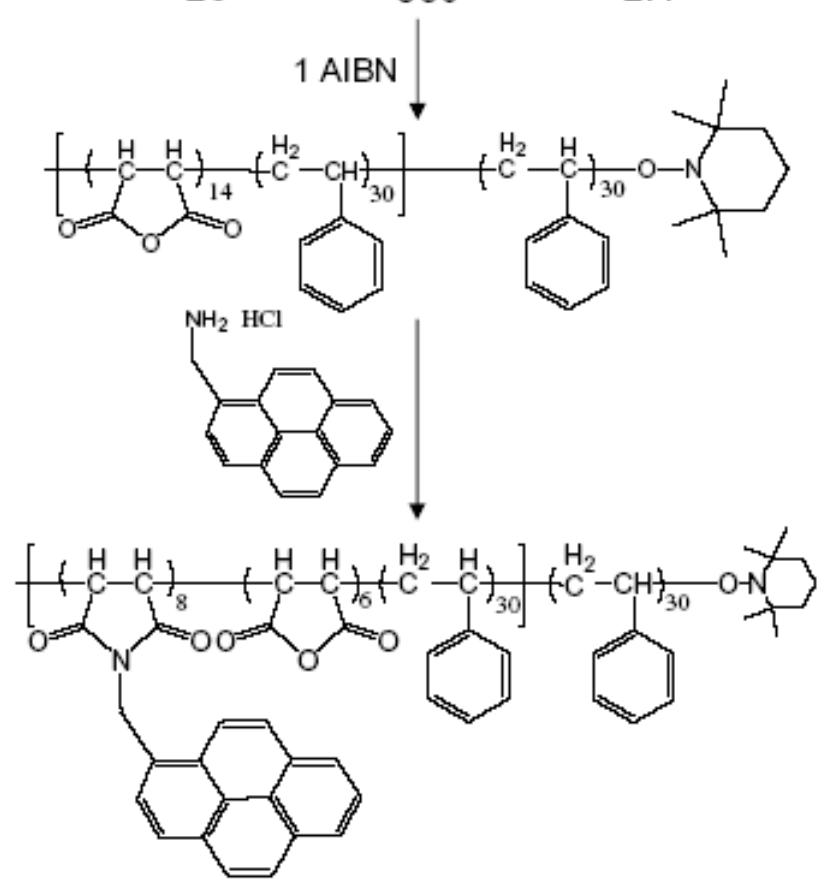

Scheme 4. Schematic representation for the preparation of pyrene functionalized poly(styrene-comaleic anhydride)-b-polystyrene (PMAS)

Britze et al. reported the synthesis of poly(para-phenylene)-b-polystyrene (PPP- $b$-PS) block copolymers using a combination of Suzuki-polycondensation (SPC) and NMP. Alkoxyaminefunctionalized poly(para-phenylene)s were initially synthesized by SPC and then its block copolymer with styrene by NMP (Scheme 5) [38].

Groison et al. reported the synthesis of well-defined P(MAA41-co-SS 10$)-b$-P(MMA-co-St)-SG1 amphiphilic block copolymer nanoobjects via nitroxide-mediated emulsion polymerization by using water-soluble macroalkoxyamine (P(MAA41-co-SS 10$)-\mathrm{SD} 1)$ as macroinitiator (Scheme 6) [39]. 

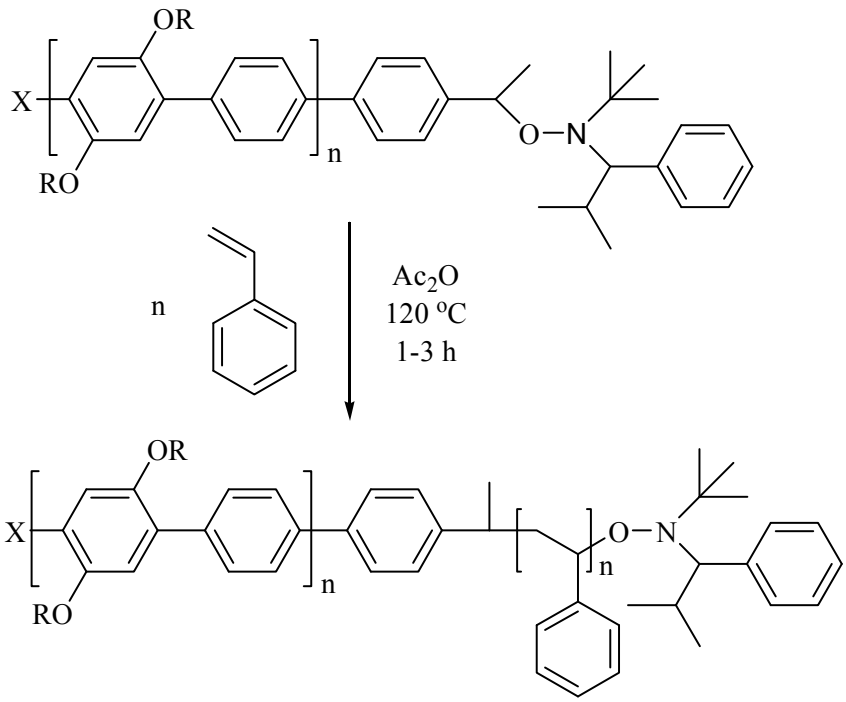

Scheme 5. Synthesis of PPP-b-PS under NMP-conditions

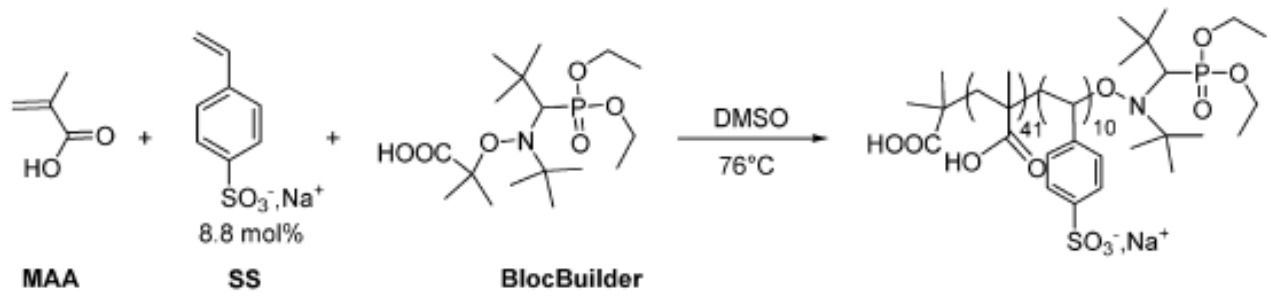

$$
\begin{array}{cc}
\left.\mathrm{P}_{\left(\mathrm{MAA}_{41}-\mathrm{CO}-\mathrm{SS}\right.}{ }_{10}\right)-\mathrm{SG} 1 \\
\text { Macroinitiator }=\mathrm{MI}
\end{array}
$$

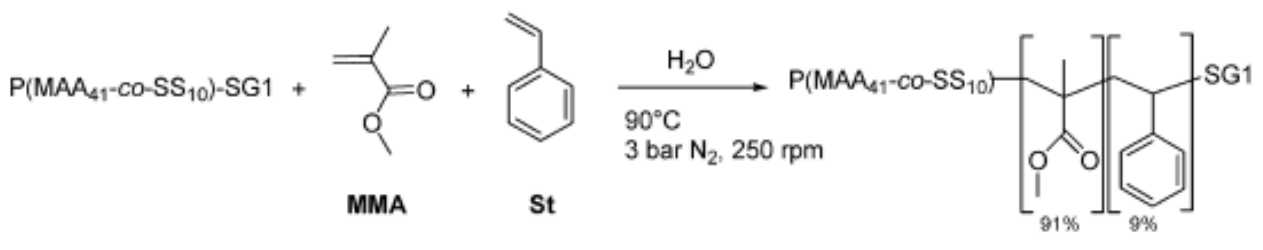

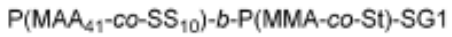

Amphiphilic block copolymer

Scheme 6. Synthesis of P(MAA41-co-SS10)-b-P(MMA-co-St)-SG1 amphiphilic block copolymers by using water-soluble macroalkoxyamine (P(MAA41-co-SS10)-SD1) via nitroxide-mediated emulsion polymerization

Ruehl et al. reported the synthesis of bidirectional alkoxyamine initiator (Scheme 7) and the preparation of a variety of symmetrical ABA type triblock copolymers based on styrene, nbutyl acrylate, t-butyl acrylate, isoprene and dimethylacrylamide by using bidirectional alkoxamine as bifunctional initiator for NMP [40]. 

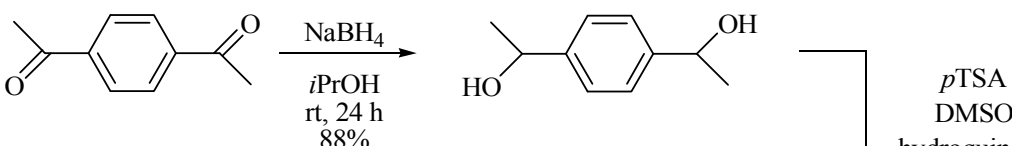

DMSO

hydroquinone

$120{ }^{\circ} \mathrm{C}, 2 \mathrm{~h}$

$47 \%$

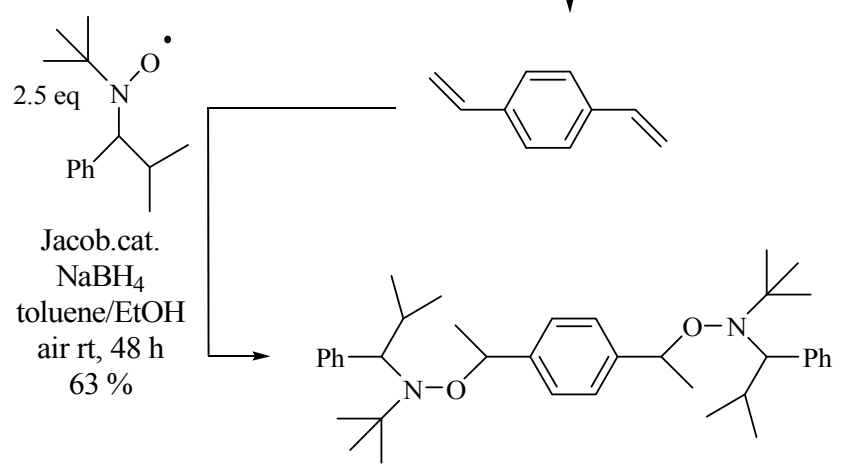

Scheme 7. Sythesis of bidirectional alkoxamine initiator for the preparation of ABA type triblock copolymer via NMP
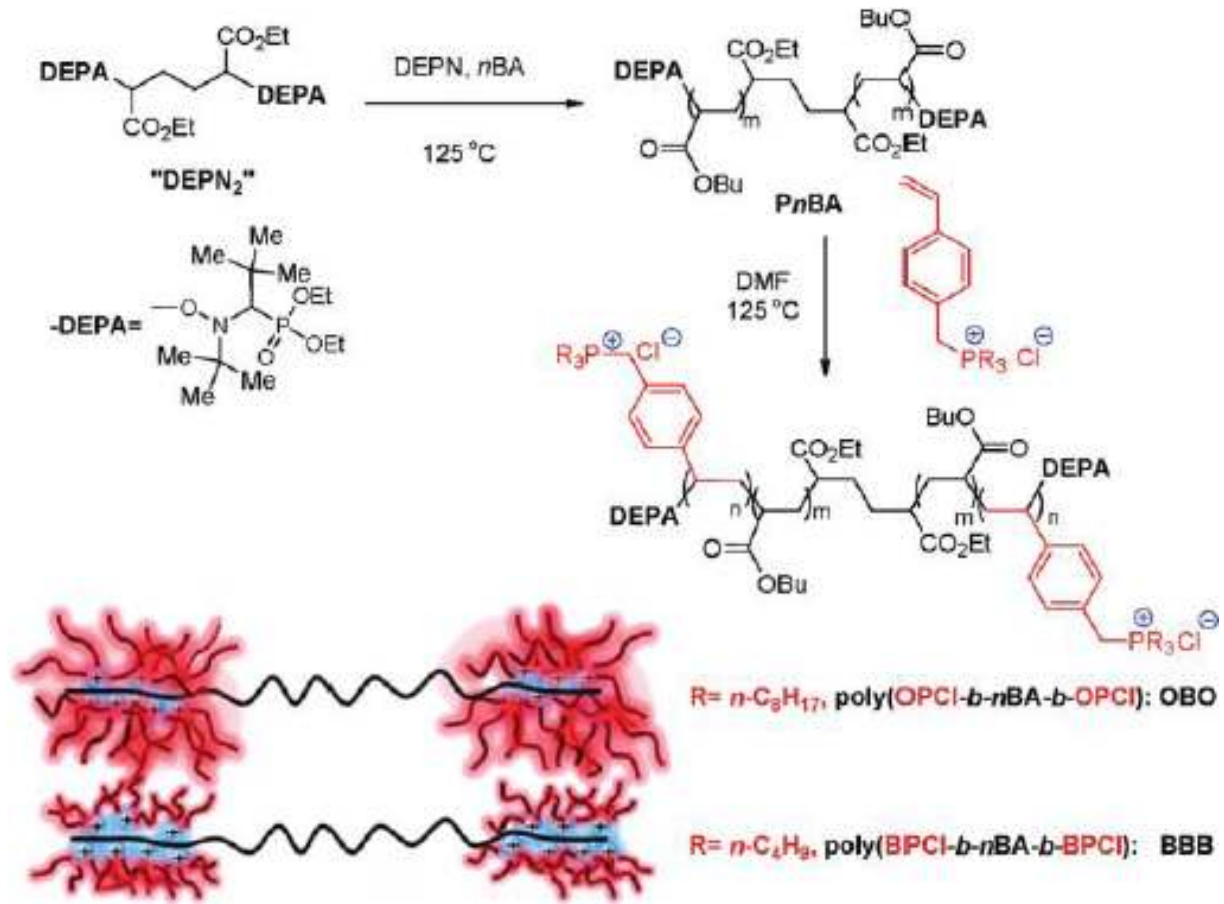

Scheme 8. Synthesis of Phosphonium-Containing Triblock Copolymers and Schematic Representation of Polymer Structures 
Phosphonium ion-containing acrylate triblock (ABA) copolymers were synthesized by Long and coworkers using NMP [41]. The polymerization of styrenic phosphonium-containing ionic liquid monomers using a difunctional alkoxyamine initiator, DEPN 2 , afforded an $A B A$ triblock copolymer with an n-butyl acrylate soft center block and symmetric phosphoniumcontaining external reinforcing blocks (Scheme 8).

The synthesis of amphiphilic triblock copolymer of polystyrene and poly(4-vinylbenzyl glucoside) via TEMPO-mediated living radical polymerization was reported by Kakuchi and coworkers [42]. 4-Vinyl benzyl glucoside peracetate 1 was polymerized with difunctional NMP initiator $\mathbf{2}$ and thus poly(4-vinylbenzyl glucoside peracetate) having TEMPO moieties on both sides of chain ends 3 was obtained. Then the polymerization of styrene was carried out using 3 as a difunctional $\mathrm{nmp}$ macroinitiator in order to obtain polystyrene- $b$-poly(4-vinylbenzyl glucoside peracetate)-b-polystyrene triblock copolymers (Scheme 9).
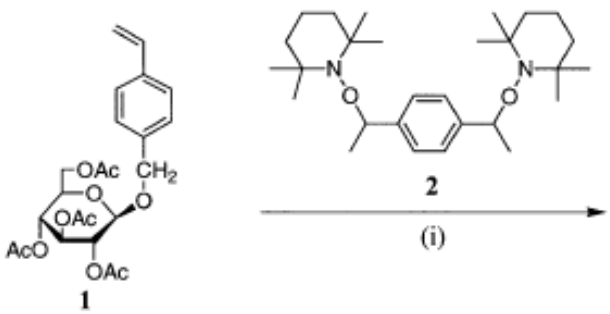

(i)

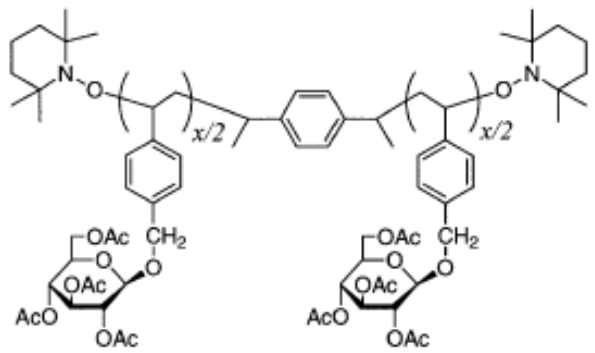

3

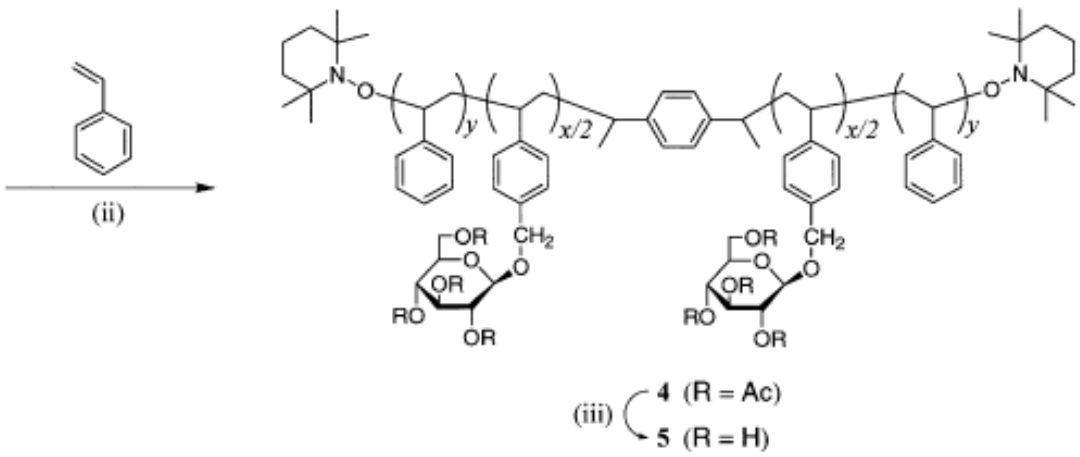

Scheme 9. Synthesis of glycoconjugated triblock copolymer via NMP

Some of block copolymers derived using NMP is given in Table 2 .

\subsection{Block copolymerization via Reversible Addition Fragmentation Chain Transfer polymerization (RAFT)}

The key component in controlled RAFT polymerization is the chain transfer agent (CTA) (Scheme 10). The CTAs used are thiocarbonylthio compounds and have the general structure 
RSC(=S)Z. Examples of RAFT agents (CTA) span all thiocarbonylthio families including dithioesters, xanthates, dithiocarbamates and trithiocarbonates. $\mathrm{Z}$ and $\mathrm{R}$ groups in the thiocarbonylthio compounds represent the activating group and homolytically leaving group, respectively. These determine the rates of addition and fragmentation. In fact, the choice of RAFT agent for a specified monomer is rather significant and affects the degree of control.

\begin{tabular}{|lllll|}
\hline $1^{\text {st }}$ Segment & $2^{\text {nd }}$ Segment & $3^{\text {rd }}$ Segment & Type of block & Ref. \\
\hline PS & PMS & - & AB & {$[43]$} \\
PS & PBA & - & AB & {$[43]$} \\
PVAc & PAN & PS & ABC & {$[44]$} \\
PVAc & PAN & PBA & ABC & {$[44]$} \\
PVAc & PAN & PVP & ABC & {$[44]$} \\
P(MMA-ran-S) & P(MMA-ran-AS) & & AB & {$[45]$} \\
PEO & PS & & AB \& ABA & {$[46]$} \\
PS & PSSA & & AB & {$[47]$} \\
\hline
\end{tabular}

Polystyrene (PS), Poly(p-methylstyrene) (PMS), Poly(n-butyl acrylate) (PBA), Poly(vinyl acetate) (PVAc), Poly(acrylonitrile) (PAN), Poly(4-vinylpyridine) (PVP), Poly(methyl methacrylate-ran-styrene) (P(MMA-ran-S)), Poly(methylmethacrylateran-4-aminostyrene) (P(MMA-ran-AS)), Poly(ethyleneoxide) (PEO), Polystyrenesulfonic acid (PSSA).

Table 2. Some of block copolymers prepared using NMP

\section{Initiation}

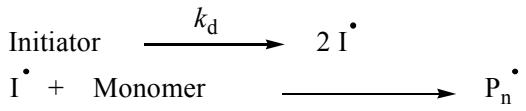

Pre-equilibrium

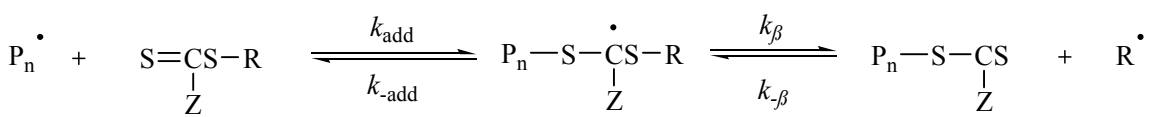

\section{Reinitiation}

$\mathrm{R}^{\bullet}+$ Monomer $\longrightarrow \mathrm{P}_{\mathrm{m}}^{\cdot}$

\section{Main Equilibrium}

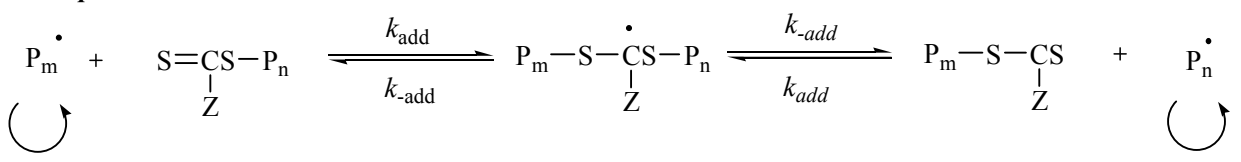

Monomer

\section{Termination}

$\dot{\mathrm{I}}, \mathrm{R}^{\bullet}, \mathrm{P}_{\mathrm{n}}, \mathrm{P}_{\mathrm{m}} \stackrel{k_{t 1}}{\longrightarrow}$ Dead polymer

Scheme 10. General scheme for the RAFT process 
The first and most thoroughly studied route towards block copolymers via the RAFT process, employs monofunctional RAFT agents (Scheme 11). The block copolymers that have been synthesized in this way all carry the RAFT functionality at the end of the chain. In the first polymerization step, monomer is inserted between the $-(\mathrm{C}=\mathrm{S}) \mathrm{S}$ moiety and the leaving group R. After polymerization is complete, the second monomer is added, polymerization is started by addition of a fresh amount of initiator, and monomer is inserted between the $-(\mathrm{C}=\mathrm{S}) \mathrm{S}$ - moiety and the end of the first block, with the RAFT functionality remaining at the chain end. Repeating this cycle of monomer addition and polymerization, it is possible to produce block copolymers. However, with this method the blocks have to be introduced in the chain step-by-step, which obviously means that to produce an n-block copolymer, a series of $\mathrm{n}$ polymerization steps is needed. To avoid inefficient blocking, this procedure should be performed starting with the monomers having the highest transfer rate to the RAFT agent. For the production of multiblock copolymers, this obviously is not the preferred route.
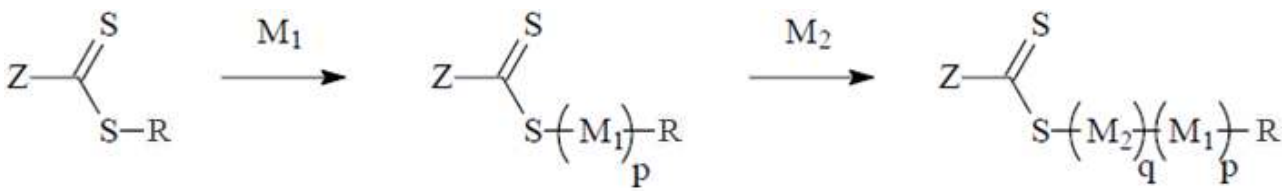

Scheme 11. Block copolymer synthesis via a monofunctional RAFT agent

A second route towards block copolymers via RAFT comprises the use of symmetrical, bifunctional RAFT agents as well as symmetrical trithiocarbonates (Scheme 12 (a)). The symmetry in these compounds ensures that both arms are of approximately the same length and composition. With these RAFT agents, the number of polymerization steps required for (multi)block copolymer synthesis can be reduced. Scheme 1 clearly demonstrates that for the synthesis of n-block copolymers, $(n+1) / 2$ polymerization steps are required. Note that only block copolymers with an odd number of blocks can be synthesized with these compounds. The major difference between a trithiocarbonate and a bifunctional RAFT agent is the way the monomer is inserted into the RAFT agent. Using a bifunctional RAFT agent, monomer is inserted into the RAFT agent at both sides of leaving group $\mathrm{R}$, while both dithiocarboxylate moieties will remain at the chain ends. In block copolymerization, the second block is thus built at the chain ends of the first block, see Scheme 12 (a). Using trithiocarbonate, monomer is inserted between both A groups and the trithiocarbonate moiety, and the trithiocarbonate moiety remains in the middle of the chain. When chain extending the first block, the second block is built in the middle of the chain, and the first block will shift to the outside of the chain as is depicted in Scheme 12 (b). In the case of trithiocarbonates, the R-S- moiety functionsas the activating group Z. [34]

The well-defined block copolymer of poly[ethylene oxide)- $b$-poly( $N$-isopropylacrlamide) (PEO- $b$-PNIPAM) was synthesized by Liang and coworkers via RAFT polymerisation using monofunctional PEO macro-RAFT agent [48] (Scheme 13). 
a)<smiles>[Z]C(=S)S[R]SC([Z])=S</smiles>

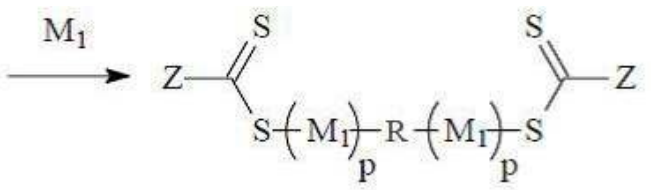

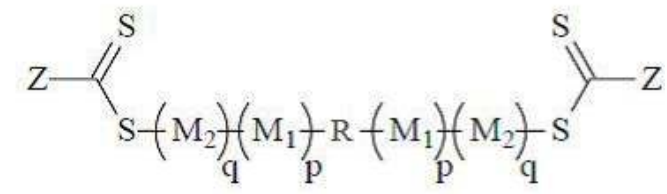

b) $\mathrm{R}-\mathrm{S}$

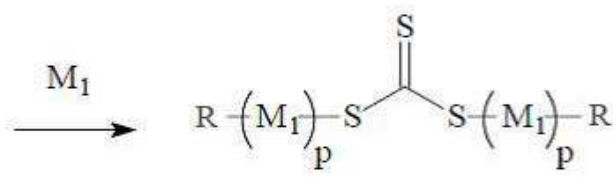
$\mathrm{M}_{2}$<smiles></smiles>

Scheme 12. Block copolymer synthesis via a bifunctional RAFT agent

Stenzel and coworkers reported the synthesis of amphiphilic block copolymers based on 2methacrylamido glucopyranose (MAG) and 5'-O-methacryloyl uridine (MAU) via RAFT copolymerization using monofunctional macro-RAFT agent (Scheme 14) [49].

Block copolymers of methyl methacrylate (MMA) and tert-butyldimethylsilyl methacrylate (TBDMSMA) have been synthesized by Bressy and coworkers via RAFT polymerization technique (Scheme 15) [50].

New block copolymers with narrow molecular weight distribution (MWD=1.04-1.14) based on (2,3-epithiopropylmethacrylate) (ETMA), methyl methacrylate (MMA) and nbutylmethacrylate ( $n \mathrm{BMA})$ have been synthesized by Petzhold and coworkers via RAFT polymerization (Scheme 16) [51] 
等<smiles>CCOCCOC(=O)CC(SC(=S)Cc1ccccc1)C(=O)O</smiles><smiles>CC(C)NC(=O)C(C)CC(C)(CC(=O)OCCOC(C)(C)C)C(=O)O</smiles>

Macro-CTA

Scheme 13. Synthetic procedure for PEO- $b$-PNIPAM by RAFT

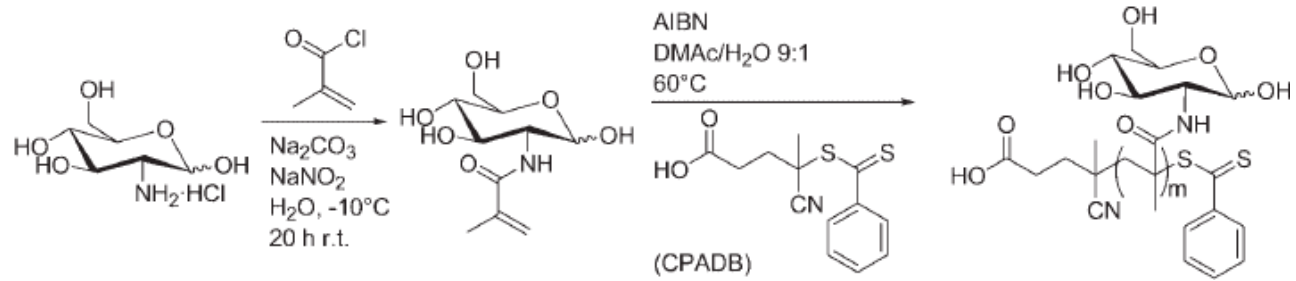

(a)<smiles>C=C(C)C(=O)OCC(O)C(O)C(O)CO</smiles><smiles>CC(C)(CCC(=O)O)CC(=O)N[C@H](NC(=S)c1ccccc1)[C@H](O)OCC(C)(C#N)C(O)O</smiles>

macroRAFT agent

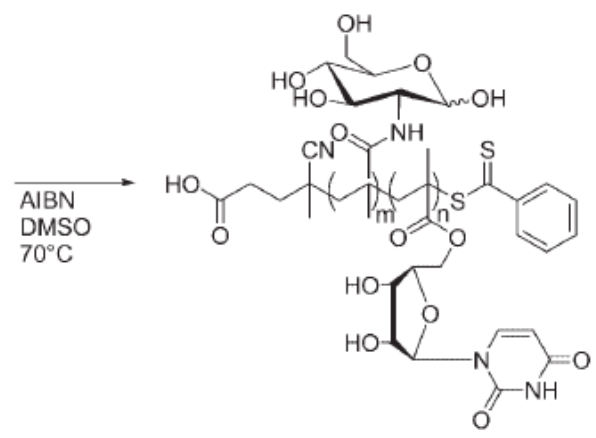

(b)

Scheme 14. (a) Synthesis of poly(2-methacrylamido glucopyranose) as a macroRAFT agent (b) synthesis of poly(2-methacrylamido glucopyranose)-b-poly( 5'-O-methacryloyl uridine) via RAFT using monofunctional macro-RAFT agent 
<smiles>C=C(C)C(=O)O[Si](C)(C)C(C)(C)C</smiles>

TBDMSMA<smiles>[R]SC(=S)c1ccccc1</smiles>

PTBDMSMA

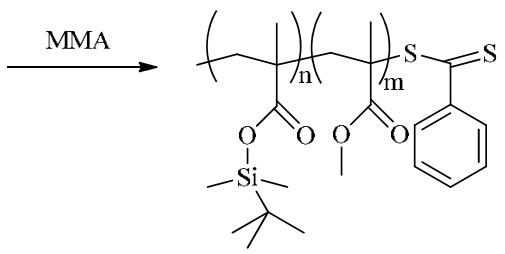

Diblock copolymer PTBDMSMA- $b$-PMMA

R:<smiles>CC(C)(C)c1ccccc1</smiles><smiles>CC(C)(C)C#N</smiles>

Scheme 15. Block copolymerization of TBDMSMA and MMA by the RAFT process<smiles>C=C(C)C(=O)OCC1CS1</smiles>

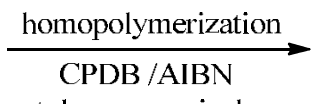
toluene or anisole<smiles>CC(C)(C)CC(C)(C(=O)OCC1CS1)C(C)(C)SC(=S)c1ccccc1</smiles><smiles>CC(C)(C)CC(C)(CC(C)(C)C)C(=O)OCC1CS1</smiles><smiles>CCCCOC(=O)C(C)(C)C(C)([GaH])SC(=S)c1ccccc1</smiles>
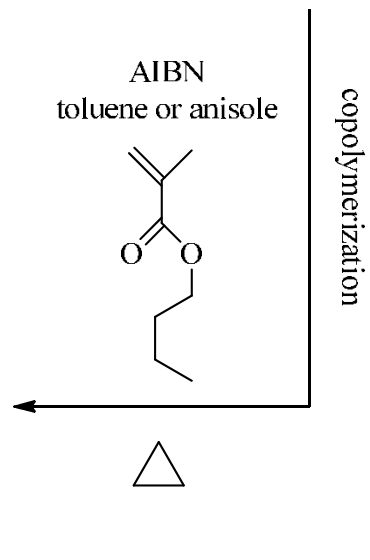

Scheme 16. Schematic representation of the synthesis of the diblock copolymer via RAFT polymerization 
Nanogel particles and double hydrophilic block copolymers were prepared by Hawker and co-workers using hydrophilic as well as amphiphilic poly(dimethylacrylamide) (PDMA) chain transfer agents (CTA) in RAFT precipitation polymerization (Scheme 17) [52].

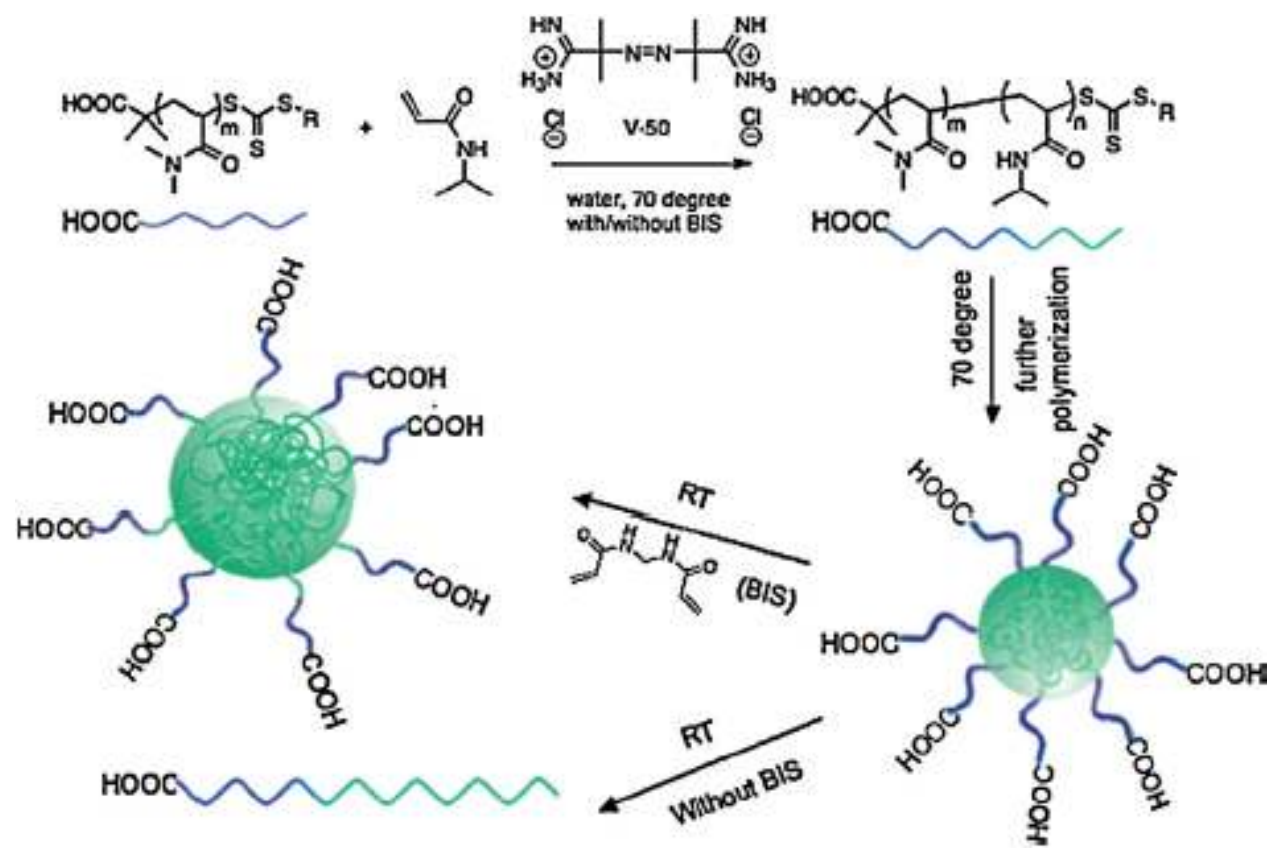

Scheme 17. Precipitation RAFT polymerization of NIPAM using a PDMA macroCTA followed by cross-linking with BIS

Guan et al. reported the synthesis of poly(dimethylsiloxane)-b-poly(2,2,3,3,4,4,4heptafluorobutyl methacrylate)- $b$-poly(styrene) (PDMS- $b$-PHFBMA- $b$-PS) triblock copolymers by two-step RAFT polymerization [53]. For this purpose, firstly xanthatecapped PDMS was prepared as the PDMS-macro-RAFT agent. Then triblock copolymers were prepared by two step RAFT polymerization using the PDMS-macro-RAFT agent (Scheme 18).

Zhang and co-workers reported the synthesis of polystyrene- $b$-poly(acrylic acid)- $b$ polystyrene (PS- $b$-PAA- $b$-PS) tri block copolymers by RAFT polymerization using $S, S^{\prime}$ $\operatorname{Bis}\left(\alpha, \alpha^{\prime}\right.$-dimethyl- $\alpha^{\prime \prime}$-acetic acid)-trithiocarbonate (BDATC) as chain transfer agent (Scheme 19) [54].

Qupicky and co-workers reported the synthesis of dually responsive (temperature- and redox-responsive) multiblock copolymers of poly( $N$-isopropylacrlamide) (PNIPAAM) and poly(dimethylaminoethylmethacrylate) (PDMAEMA) by RAFT polymerization [55]. Welldefined bis(dithioester)-functionalized PNIPAM 3 and PDMAEMA 4 were prepared using 1,4-bis(thiobenzoylthiomethyl)benzene 1 and 1,4-bis(2-(thiobenzoylthio)prop-2-yl)benzene 2 
as RAFT agents, respectively. Multiblock copolymers were synthesized in a single aminolysis/oxidation step from the bis(dithioester)-terminated PNIPAAM and PDMAEMA (Scheme 20).<smiles>CCCC[Si](C)(C)O[Si](C)(C)CCCOCCOC(=O)C(C)(C)SC(=S)OCC</smiles>

(PDMS-macro RAFT agent)

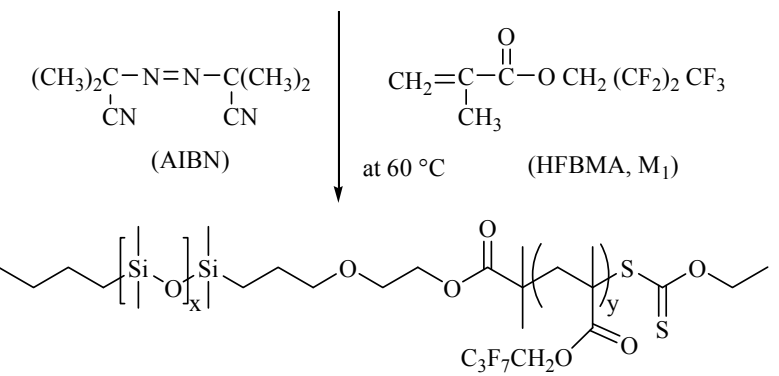

(PDMS- $b$-PHFBMA-macro RAFT agent)

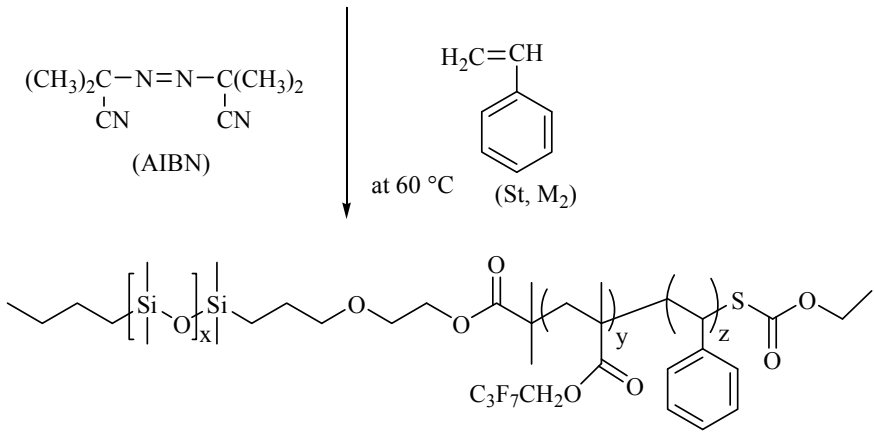

(PDMS- $b$-PHFBMA- $b$-PS)

Scheme 18. The synthesis of PDMS- $b$-PHFBMA- $b$-PS triblock copolymers by two-step RAFT polymerization

Baum and Brittain reported the synthesis of surface immobilized diblock copolymer brush (Si/SiO $2 / / P S-b-P D M A)$ using RAFT [56]. Styrene, methyl methacrylate, and $N, N-$ dimethylacrylamide brushes were prepared under RAFT conditions using silicate surfaces that were modified with surface-immobilized azo initiators. Films with controlled thicknesses were produced. RAFT was also used to synthesize PS- $b$-PDMA and PDMA- $b$ PMMA block copolymer brushes that displayed reversible surface properties upon treatment with block-selective solvents. (Scheme 21). 
<smiles>CC(C)(SC(=S)SC(C)(C)C(=O)O)C(=O)O</smiles><smiles>CC(C)(CSC(=S)SC(CC(C)(C)c1ccccc1)CC(C)(CC(C)(C)C(=O)O)c1ccccc1)C(=O)O</smiles>

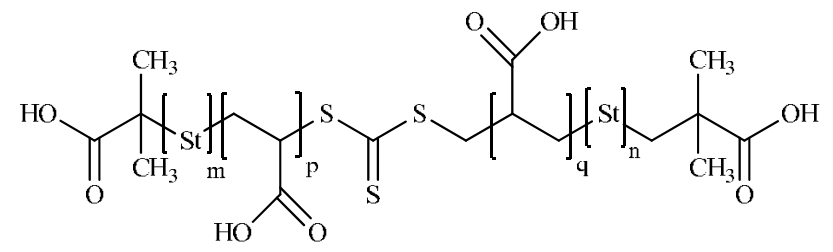

Scheme 19. The synthesis of PS- $b$-PAA-b-PS tri block copolymers by RAFT polymerization

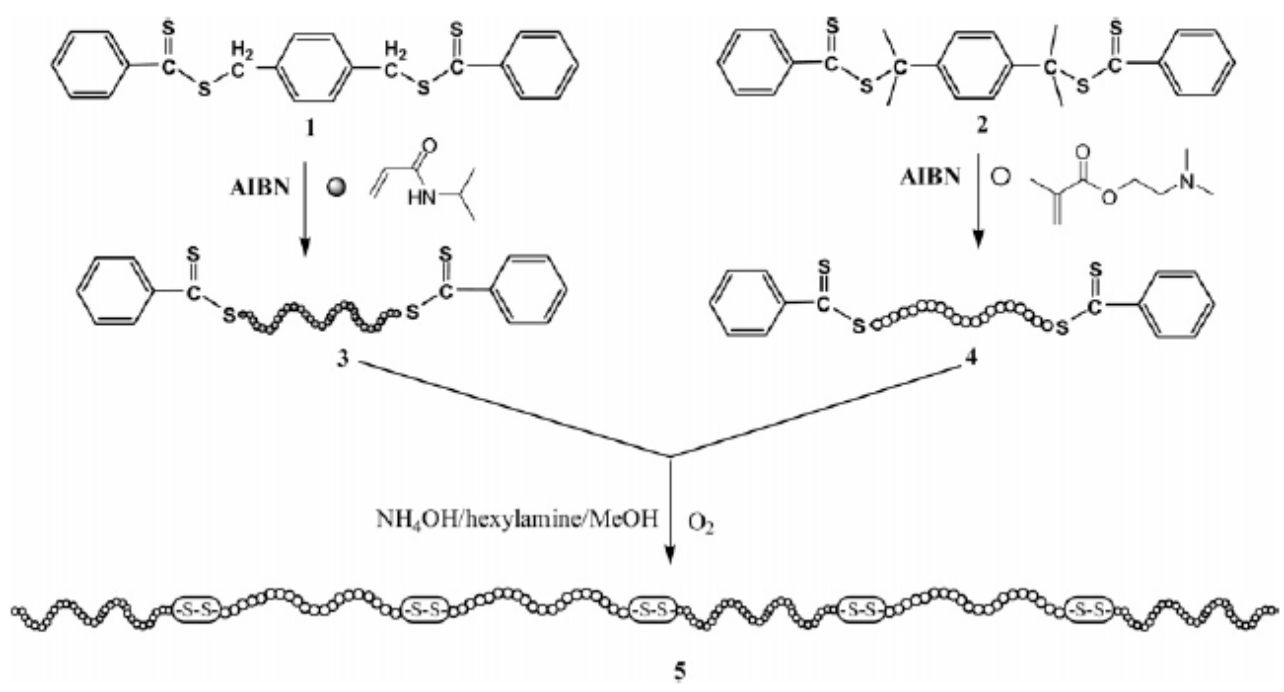

Scheme 20. The synthesis of dually responsive multiblock copolymers of PNIPAM and PDMAEMA by RAFT polymerization

Some of block copolymers derived using RAFT polymerization is given in Table 3. 


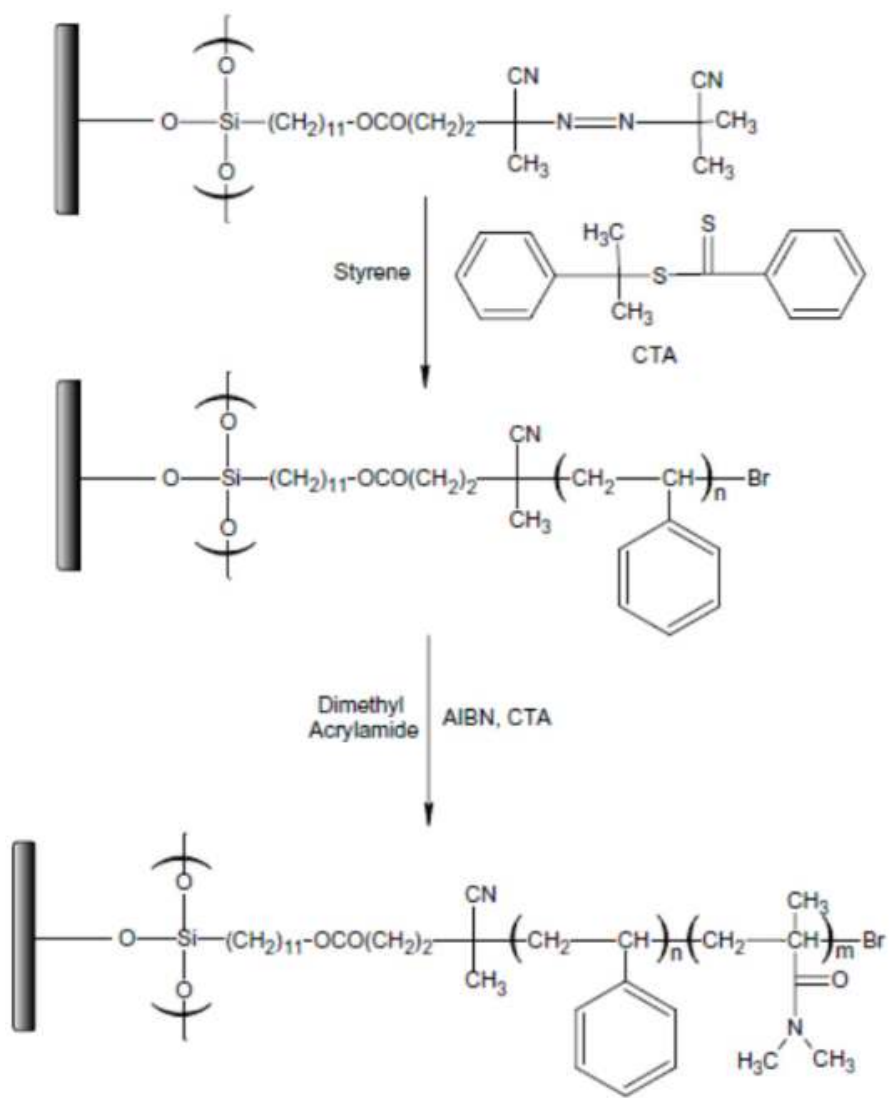

Scheme 21.Synthesis of surface immobilized diblock copolymer brush (Si/SiOz//PS- $b$-PDMA) using RAFT.

\begin{tabular}{|l|l|l|l|l|}
\hline $1^{\text {st }}$ Segment & $2^{\text {nd }}$ Segment & $3^{\text {rd }}$ Segment & Type of block & Ref. \\
\hline PMAOEGlc & P(6-O-MAMMan $)$ & - & $\mathrm{AB}$ & {$[57]$} \\
PMAOEGlc & P(6-O-MAMGlc $)$ & - & $\mathrm{AB}$ & {$[57]$} \\
PNIPAAM & PMAGlcC 5 & - & $\mathrm{AB}$ & {$[58]$} \\
PNIPAAM & PDEAEMA & - & $\mathrm{AB}$ & {$[59,60]$} \\
PNIPAAM & PAGA & - & $\mathrm{AB}$ & {$[61$} \\
PVAc & PVPv & - & $\mathrm{AB}$ & {$[62]$} \\
PVAc & PVBz & - & $\mathrm{AB}$ & {$[62]$} \\
P(6-O-MAMGlc) & PHEMA & - & $\mathrm{AB}$ & {$[63]$} \\
\hline
\end{tabular}

Poly(2-methacryloxyethyl glucoside) (PMAOEGlc), poly(methyl 6-O-methacryloyl-D-mannoside) P(6-O-MAMMan), poly(methyl 6-O-methacryloyl-D-glucoside) P(6-O-MAMGlc), Poly(N-isopropylacrylamide) (PNIPAAM), Poly(Dglucofuranosyl)-6-methacrylamido hexanoate (PMAGlcC5), Poly(2-(diethylamino)ethyl methacrylate) (PDEAEMA), poly(acryloyl glucosamine) (PAGA), poly(vinyl acetate) (PVAc), poly(vinyl pivalate) (PVPv), poly(vinyl benzoate) (PVBz), poly(2-hydroxyethyl methacrylate) (PHEMA).

Table 3. Some of block copolymers prepared using RAFT polymerization 


\subsection{Block copolymerization via Atom Transfer Radical Polymerization (ATRP)}

Of the several controlled/"living" free radical polymerization techniques, ATRP seems to be the most versatile, being able to polymerize a variety of monomers, method to prepare block and graft copolymers. ATRP enables the synthesis of a wide range of (co)polymers with controlled molecular weight, narrow molecular weight distribution, and range of architectures and functionalities.

The synthesis of well-defined $\mathrm{AB}$ type diblock copolymers from styrene (S) and methyl acrylate (MA) via ATRP was reported by Schubert and co-workers [64]. Both synthetic routes starting with styrene as first block or methyl acrylate as first block are shown in Scheme 22.

\begin{tabular}{|l|l|l|ll|}
\hline $1^{\text {st }}$ Segment & 2nd Segment & 3rd eegment & Type of block & Ref. \\
\hline PMMA & P(n-BA) & PMMA & ABA & {$[67]$} \\
PMMA & PMA & PMMA & ABA & {$[67]$} \\
PDMS & PS & - & AB & {$[68]$} \\
PS & PMAIpGlc & - & AB & {$[69]$} \\
PS & P(n-BA) & - & AB & {$[70]$} \\
PS & P(n-BA) & PS & ABA & {$[70]$} \\
PS & PE & PS & ABA & {$[71]$} \\
PS & PB & PS & ABA & {$[71]$} \\
MPEG & PDMAEMA & PBMA & ABC & {$[72]$} \\
MPEG & PBMA & PDMAEMA & ABC & {$[72]$} \\
PS & PTMDS & PS & ABA & {$[73]$} \\
PMPC & PDMAEMA & - & AB & {$[74]$} \\
PMPC & PDPAEMA & - & AB & {$[74]$} \\
PBMA & PDMAEMA & - & AB (brushes) & {$[75]$} \\
PAMA & PS & PAMA & ABA & {$[76]$} \\
PAMA & PMMA & PAMA & ABA & {$[76]$} \\
PAMA & PBA & PAMA & ABA & {$[76]$} \\
PSSNa & PMMA & - & AB & {$[77]$} \\
PSSNa & PMMA & PSSNa & ABA & {$[77]$} \\
PCL & P(MAPEO-co-DIGaMA) & - & AB & {$[78]$} \\
PGEMA & PDEGMA & - & AB & {$[79]$} \\
\hline
\end{tabular}

Polymethylmethacrylate (PMMA), Poly(n-butylacrylate) (P(n-BA)), polymethylacrylate (PMA), poly(dimethylsiloxane) (PDMS), polystyrene (PS), poly(3-O-methacryloyl-1,2:5,6-di-O-isopropylidene-D-glucofuranose) (PMAIpGlc), polyester and/or polyether (PE), polybutadiene (PB), methoxy-poly(ethyleneglycol) MPEG, poly(2-

(dimethylamino)ethylmethacrylate) (PDMAEMA), Poly(n-butylmethacrylate) (PBMA), poly(tetramethyldisiloxane) (PTMDS), poly(2-(methacryloyloxy)-ethylphosphorylcholine) (PMPC), poly(2-(diisopropylamino)ethylmethacrylate) (PDPAEMA), poly(allyl methacrylate) (PAMA), poly(sodium styrene sulfonate) (PSSNa), polycaprolactone (PCL), $\omega$ methacrylate poly(ethylene oxide) (MAPEO), 6-O-methacryloyl-1,2:3,4-di-O-isopropylidene-D-galactopyranose (DIGaMA), poly(2-glucosyloxyethyl methacrylate) (PEGMA), poly(diethyleneglycolmethacrylate) (PDEGMA)

Table 4. Block copolymers prepared using ATRP 
<smiles>C=Cc1ccccc1</smiles>

styrene<smiles>CCOC(=O)C(C)(Br)Br</smiles>

EBIB<smiles>CCOC(=O)C(C)(C)CC(C)C(Br)c1ccccc1</smiles>

methyl acrylate

PS $-b-$ PMA<smiles>C=CC(=O)OC</smiles>

methyl acrylate<smiles>CCOC(=O)C(C)(C)Br</smiles><smiles>CCCCCCCCCCCCCC(C)(Br)Br</smiles>

EBIB<smiles>CCOC(=O)C(C)(C)CC(C)C(=O)OC</smiles>

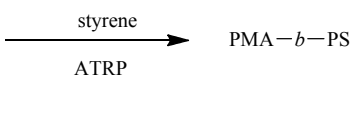

Scheme 22. Schematic representation of synthetic strategy to block copolymers from styrene and methyl acrylate

The synthesis of ABA type triblock copolymers of poly(2-(dimethylamino)ethylmethacrylate)$b$-polycaprolactone- $b$-poly(2-(dimethylamino) ethylmethacrylate) (PDMAEMA- $b$-PCL- $b$ PDMAEMA) via ATRP of DMAEMA using difunctional polycaprolactone (Br-PCL-Br) as macroinitator was reported by Jhurry and Motala-Timol (Scheme 23) [65].

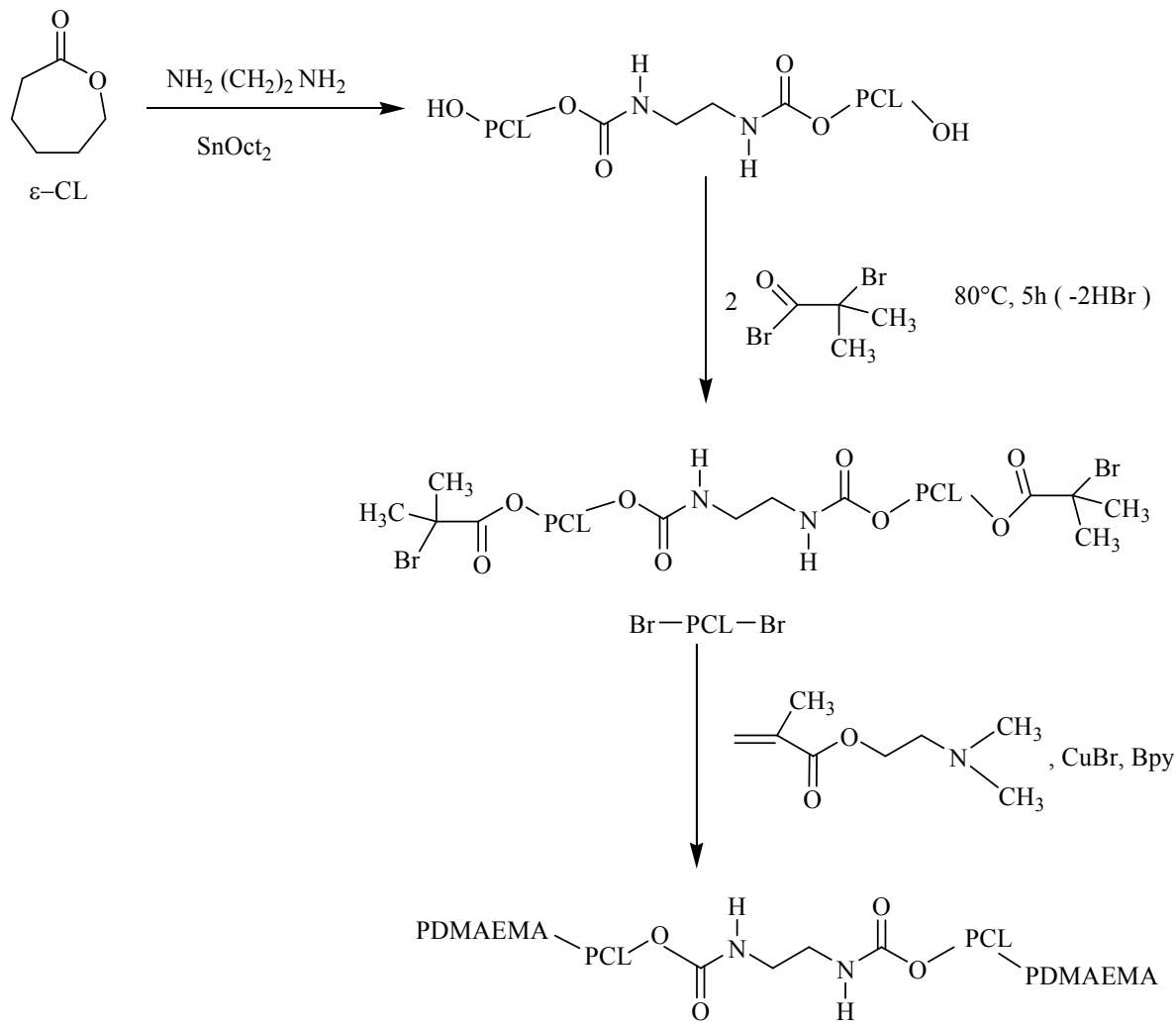

Scheme 23. Synthesis of triblock PDMAEMA-b-PCL- $b$-PDMAEMA copolymer 
Huang et al. reported the preparation of amphiphilic triblock PMMA- $b$-PDMAEMA- $b$ PMMA and poly(methyl acrylate)- $b$-poly(methyl methacrylate)- $b$-poly(hydroxyethyl methacrylate) (PMA- $b$-PMMA- $b$-PHEMA) copolymer brushes grown from a surface via sequential low-temperature ATRP (Scheme 24) [66]

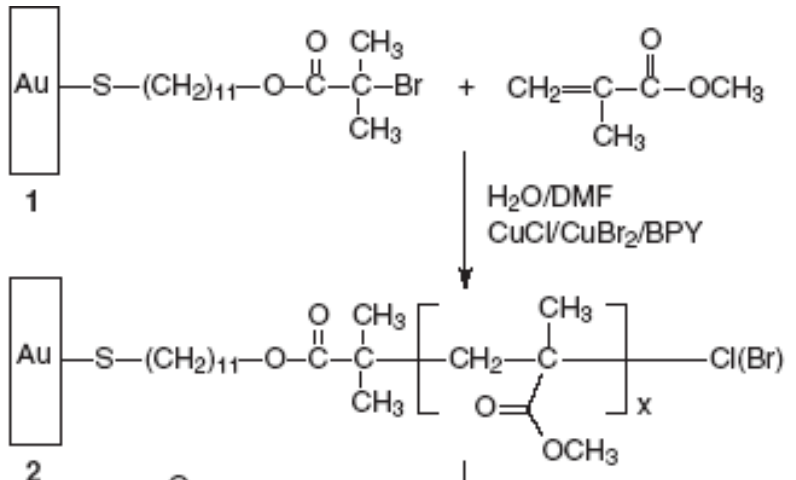

2

$\mathrm{CuBr} / \mathrm{CuBr}_{2} / \mathrm{HMTETA}$

DCB, RT

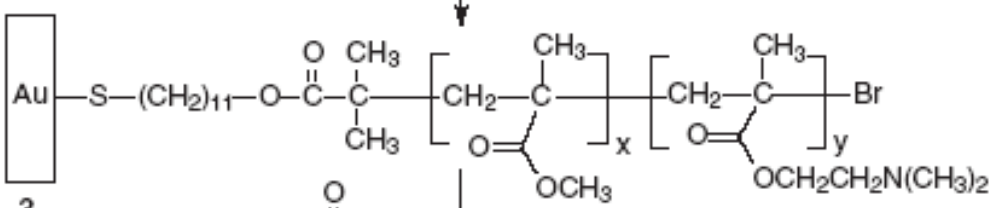

3
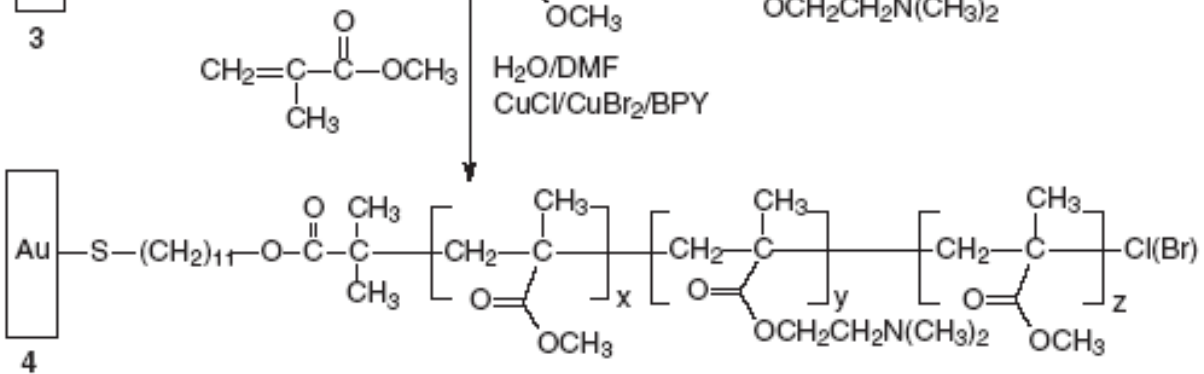

Scheme 24. Synthesis of triblock copolymer brushes from gold surfaces by sequential ATRP.

Recently many studies on the synthesis of block copolymers via ATRP in the literature have been reported due to its advantages. Some of them are listed in Table 4.

\section{Graft copolymerization}

Graft copolymers are another class of segmented copolymers. As informed previously, many basic characteristics of block copolymers and graft copolymers are similar and no major difference exists between block copolymer synthesis and graft copolymer synthesis. The location of sites and functions are at the chain ends or on the chains, respectively: 


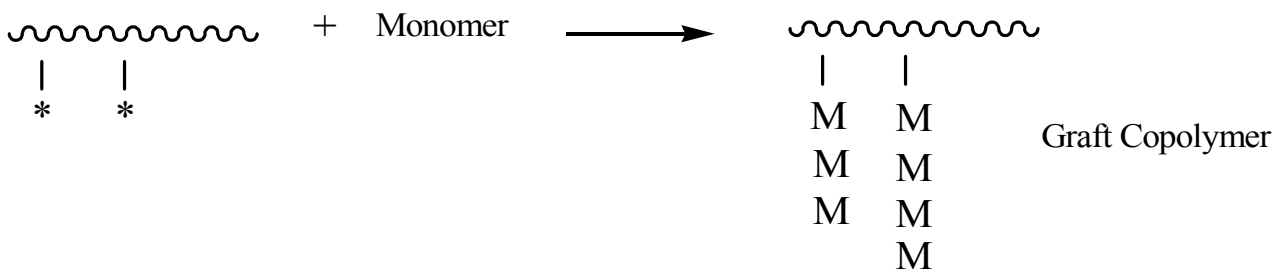

"Grafting" is a method wherein monomers are covalently bonded (modified) onto the polymer chain. Graft copolymers can be obtained with three general approachs [80]:

1. Grafting-onto: A preformed polymer with a reactive end-group is used a precursor, and then attached to the backbone. This method involve reaction of functional groups $(\mathrm{Y})$ located at chain ends of one kind of polymer with another functional groups $(X)$ which distributed randomly on the main chain of the other polymer (backbone).

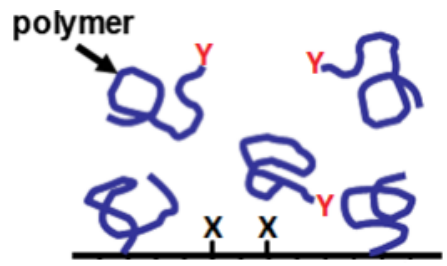

Figure 6. Schematic presentation of Grafting-onto

2. Grafting-from: The monomer is grafted from the backbone. "Grafting-from" is significantly more versatile than "grafting-onto".

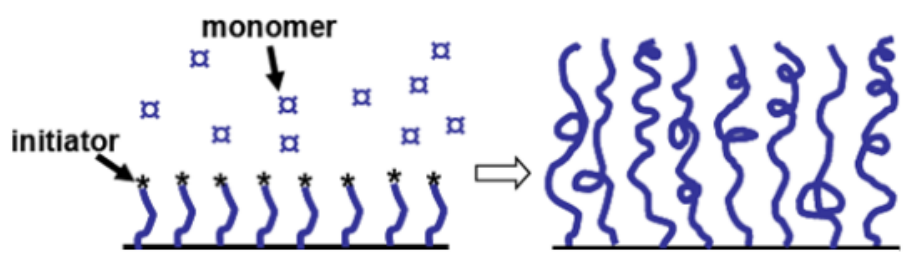

Figure 7. Schematic presentation of Grafting-from

3. Grafting-through in other words grafting via surface-attached monomers (macromonomers): In this approach, polymerizations are carried out at the presence of polymers (backbone) onto which functionalized monomers have been attached. The surface-attached monomers are incorporated into growing polymer chains in the same way as the monomers in solution (the monomers in solution are usually different from the surface-attached ones).

\subsection{Graft copolymerization via NMP}

Hua et al. prepared polystyrene grafted chitosan [81] (Scheme 25) and poly(sodium 4styrenesulfonate) grafted chitosan [82] (Scheme 26) via NMP using chitosan-TEMPO macroinitiator. 


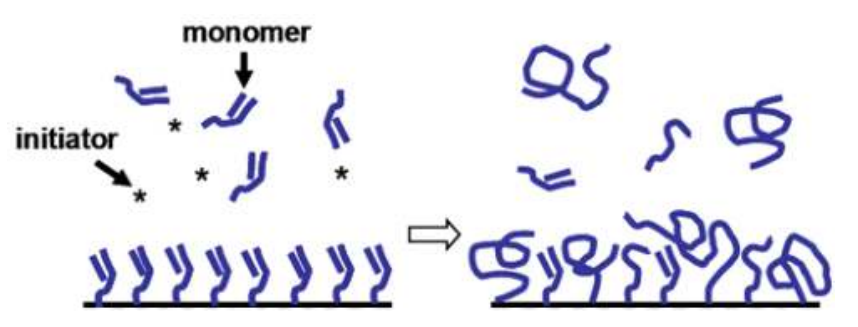

Figure 8. Schematic presentation of Grafting-through

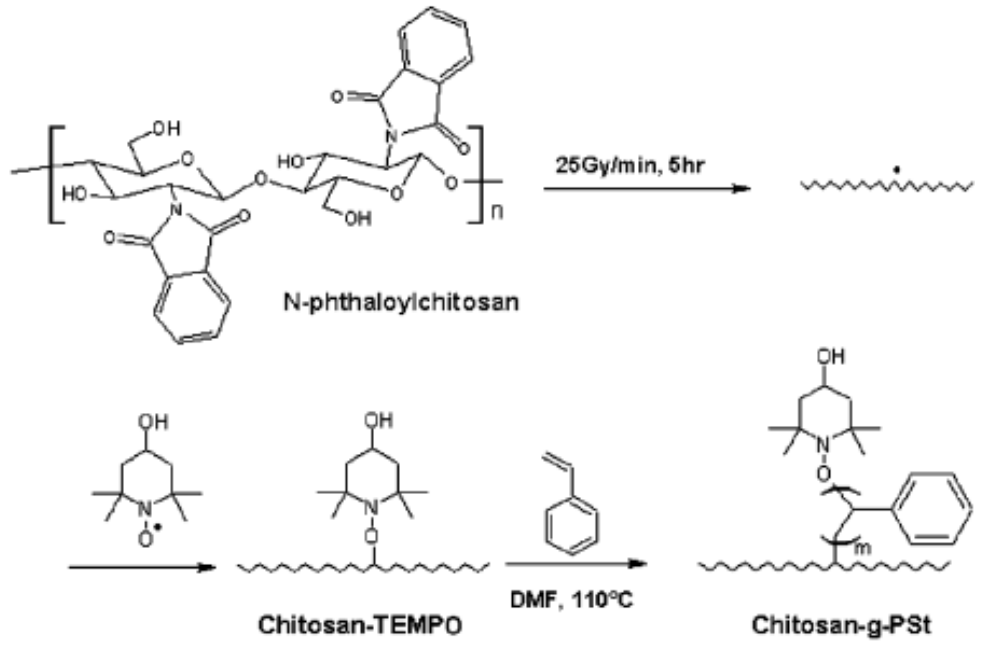

Scheme 25. Synthesis of Chitosan-g-PSt by NMP
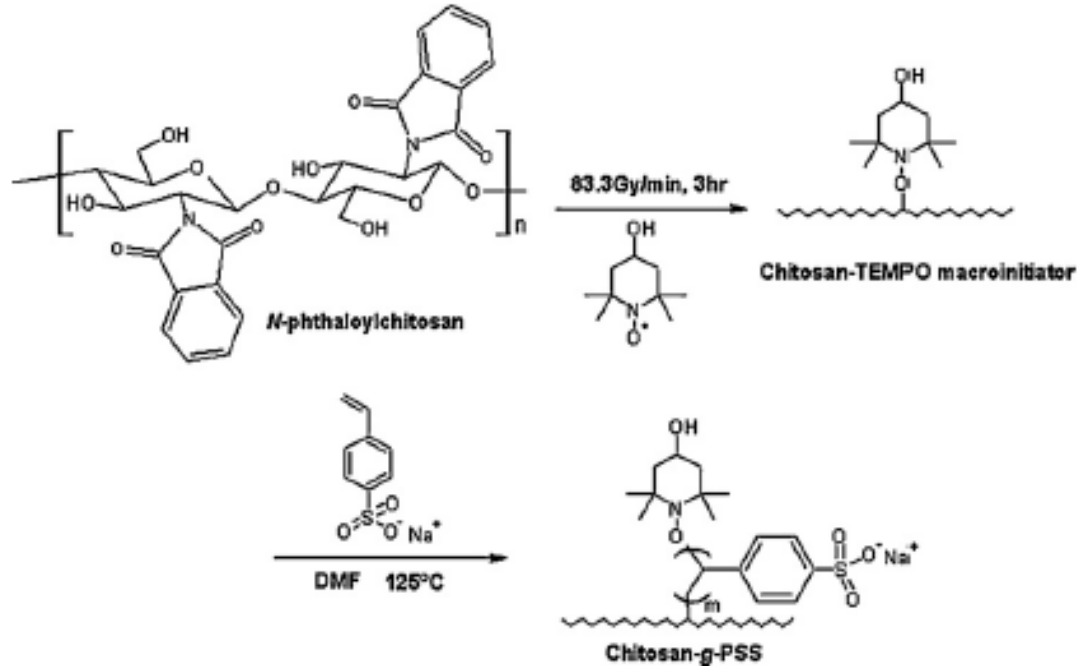

Scheme 26. Synthesis of Chitosan-g-PSS by NMP 
Jaymand reported the synthesis and characterization of novel type poly(4-chloromethyl styrene-graft- 4-vinylpyridine)/ $\mathrm{TiO}_{2}$ nanocomposite via NMP [83]. Firstly, poly(4chloromethyl styrene)/ $/ \mathrm{TiO}_{2}$ nanocomposite carrying TEMPO groups (PCMS-TEMPO/TiO 2 ) was synthesized (Scheme 27) and then the controlled graft copolymerization of 4vinylpyridine was initiated by PCMS-TEMPO/TiO2 as a macroinitiator (Scheme 28).
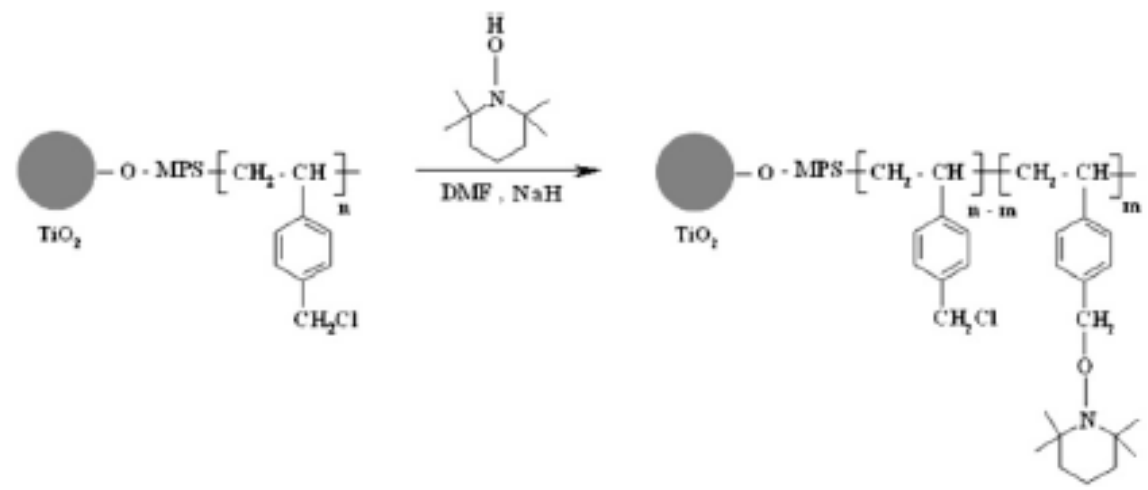

Scheme 27. Synthesis of PCMS-TEMPO/TiO 2 macroinitiator
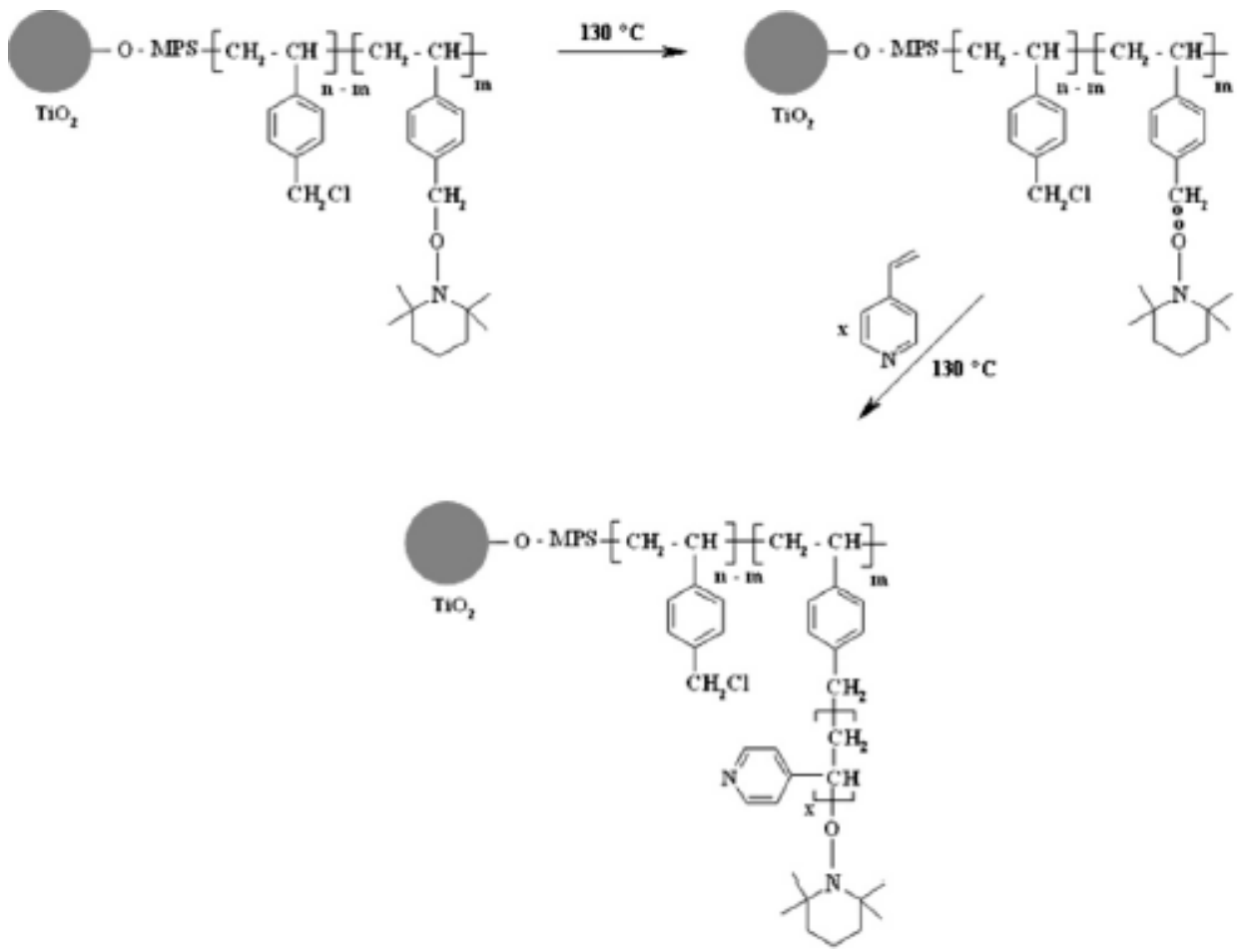

Scheme 28. Nitroxide-mediated living radical polymerization of 4-vinylpyridine onto PCMS$\mathrm{TEMPO} / \mathrm{TiO}_{2}$ macroinitiator 


\subsection{Graft copolymerization via RAFT polymerization}

Neoh and co-workers reported the preparation of graft copolymers of poly(ethylene glycol)methyl ether methacrylate (PEGMA) with poly(vinylidene fluoride) (PVDF) [84] and poly(acrylic acid) (PAAc) with poly(vinylidene fluoride) (PVDF) [85] via RAFT polymerization. The peroxides generated on the ozone-pre-treated PVDF facilitated the thermally initiated graft copolymerization of PEGMA and PAAc in the RAFT-mediated process respectively (Scheme 29).
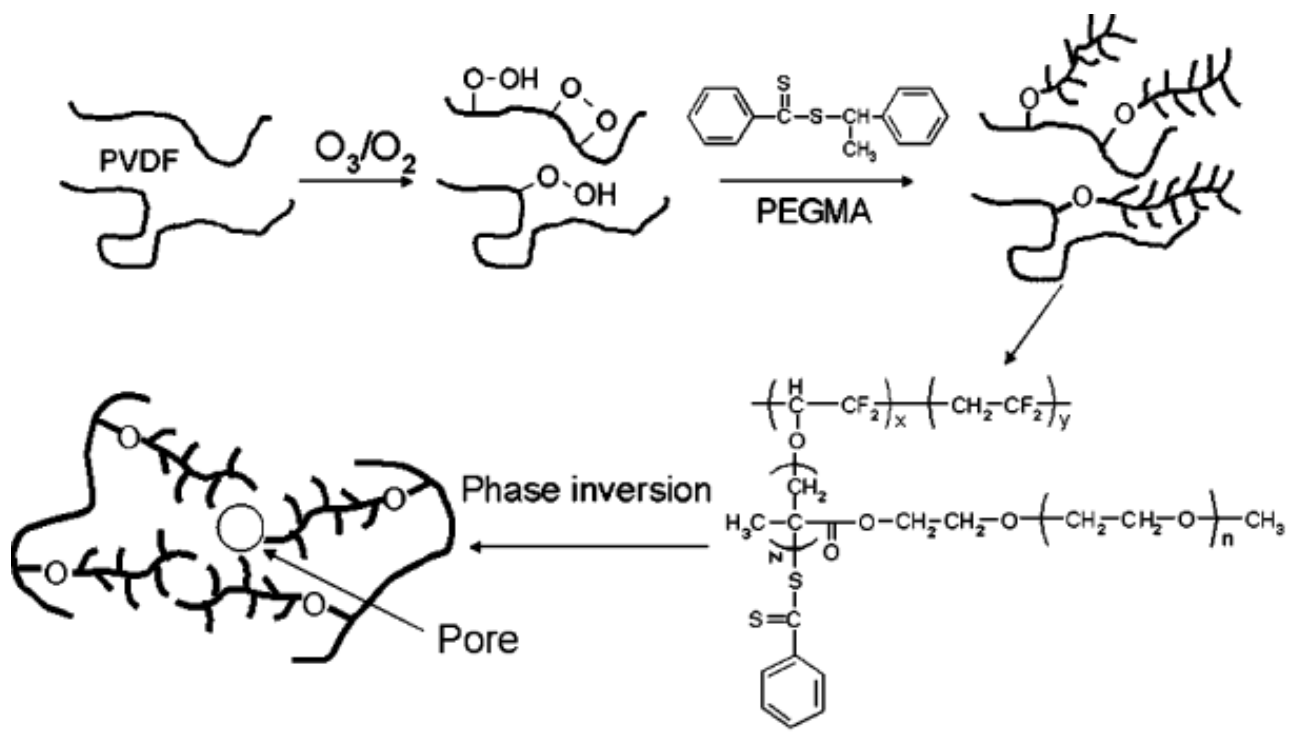

Scheme 29. Schematic illustration of the processes of PEGMA graft copolymerization with the ozonepreactivated PVDF backbone by RAFT-mediated polymerization and the preparation of the PVDF- $g$ PEGMA MF membrane by phase inversion.

Perrier and co-workers performed grafting of styrene from cellulose substrate via RAFT polymerization [86]. The hydroxyl groups of cellulose fiber were converted into thiocarbonyl-thio chain transfer agent, and were further used to mediate the RAFT polymerization of styrene (Scheme 30).

Stenzel and co-workers prepared stimuli-responsive glycopolymer brushes composed of $\mathrm{N}$ acryloyl glucosamine (AGA) and NIPAAM using RAFT polymerization [87]. The RAFT agent was immobilized on the surface of a treated silicon waver via covalent attachment using the Z-group (Scheme 31)

Hua et al. reported the controlled grafting modification of chitosan via RAFT polymerization using chitosan-RAFT agent. The chitosan was first modified with $S$-1-dodecyl- $S^{\prime}-\left(\alpha, \alpha^{\prime}-\right.$ dimethyl- $\alpha$ "-acetic acid)trithiocarbonate (DDACT) to serve as RAFT agent, and then the controlled grafting polymerization of acrylic acid were performed [88]. Morimoto et al. reported the grafting of NIPAAM on polysaccarides by RAFT polymerization [89]. 
Mespouille et al. also reported the grafting of NIPAAM on aliphatic polycarbonates by RAFT polymerization [90]. Synthesis of poly(tert-butl methacrylate) graft-poly(dimethylsiloxane) graft copolymers via RAFT polymerization was reported by Hou and co-workers [91].

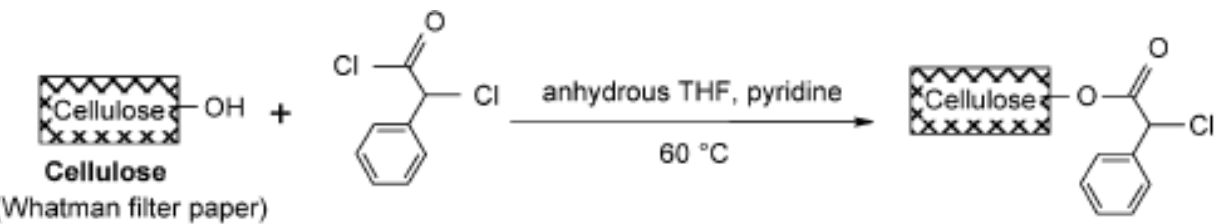

\section{2-Chloro-2-phenylacetyl chloride}

(CPAC)

\section{Cellulose-CPAC}

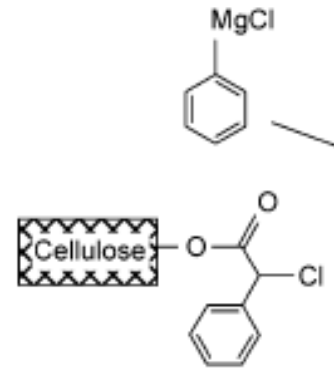

Cellulose-CPAC

\section{$\mathrm{CS}_{2}$, anhydrous $\mathrm{THF}_{1} 40^{\circ} \mathrm{C}$}
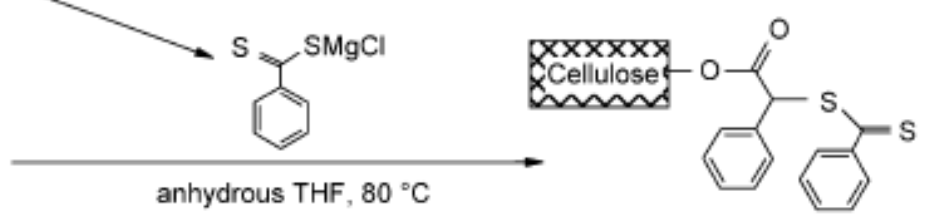

Cellulose-CTA

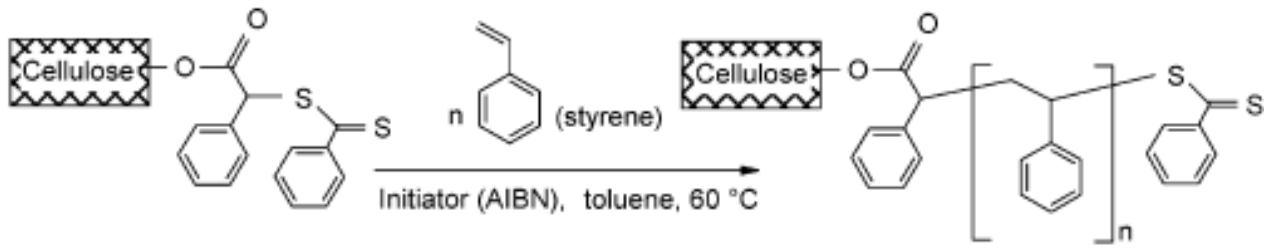

\section{Cellulose-CTA}

Cellulose-g-poly(styrene)

Scheme 30. Synthesis of cellulose chain transfer agent for RAFT polymerization and their use to mediate styrene polymerization

\subsection{Graft copolymerization via ATRP}

In recent year's chemical modification and particularly surface modification of natural polymers such as collagen, cellulose, chitosan etc. has become a popular method for providing a material with desirable properties for practical applications. Particularly ATRP has been proven to be versatile for the grafting of vinyl monomers on to natural polymers.

El Tahlawy \& Hudson prepared chitosan macroinitiators by acetylation of chitosan with 2bromo-isobutyryl bromide (EBIB) in the presence of pyridine as a base. Then chitosan macroinitiator was used to polymerize a methoxy-poly(ethylene glycol)methacrylate 
(MeO(PEG)MA) monomer [92]. Using a similar approach, Li et al. proposed the controlled synthesis of chitosan beads grafted with polyacrylamide via surface-initiated ATRP [93]. The bromide-end groups were immobilized on the surfaces of chitosan beads through reaction of $-\mathrm{NH}_{2}$ or $-\mathrm{OH}$ groups with EBİB (Scheme 32).
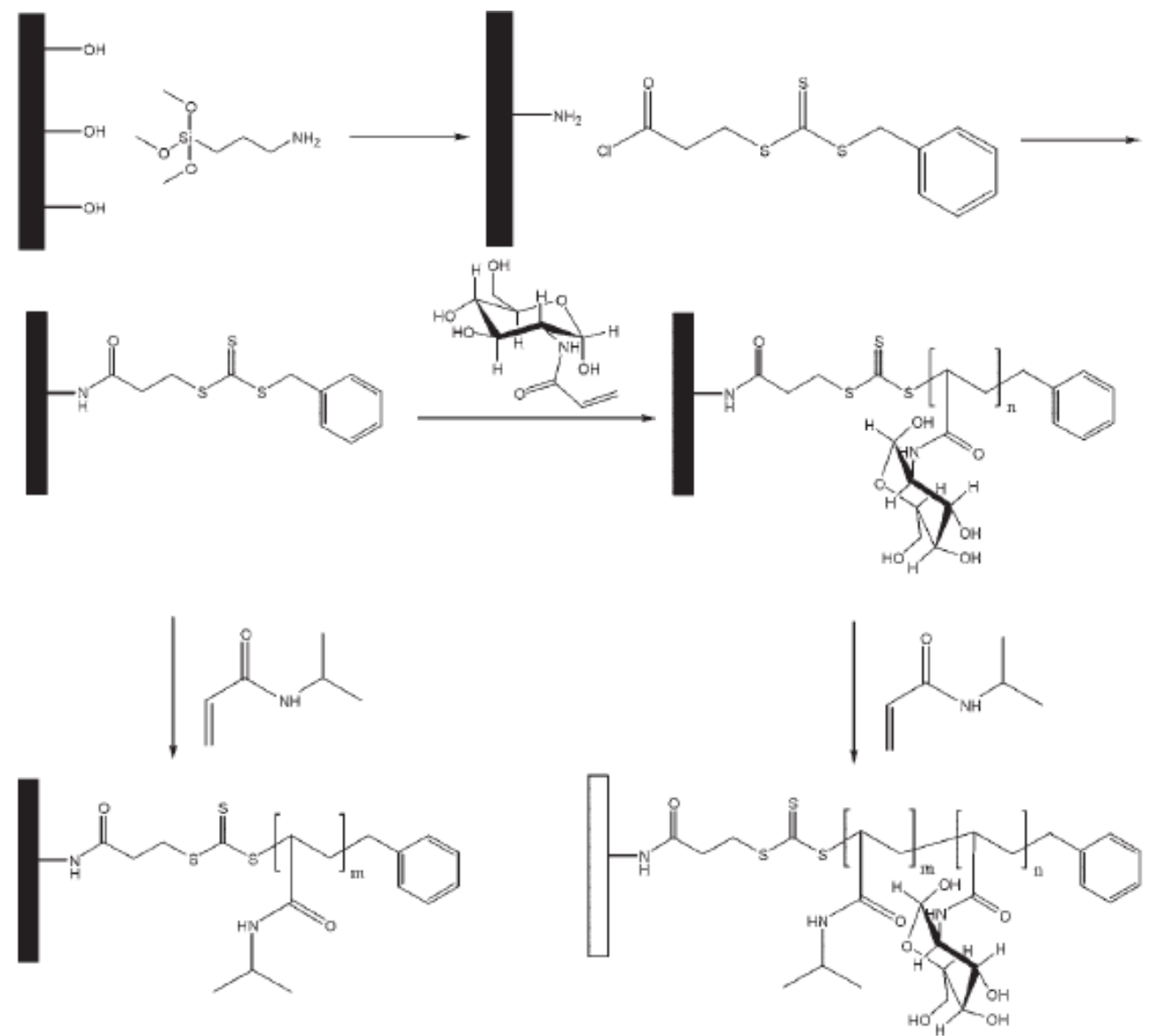

Scheme 31. Synthesis of stimuli-responsive glycopolymer brushes using RAFT polymerization via Zgroup approach

Arslan et al. reported the synthesis of brush type graft copolymers of poly(3hydroxybutyrate) (PHB) and poly(3-hydroxyoctanoate) (PHO) with methylmethacrylate, (MMA), styrene, (S), and n-butylmethacrylate, (n-BuMA) by using ATRP via "grafting from" technique [94,95]. Firstly PHB and PHO were chlorinated by passing chlorine gas through their solution in $\mathrm{CHCl}_{3} / \mathrm{CCl}_{4}(75 / 25 \mathrm{v} / \mathrm{v})$ mixture and $\mathrm{CCl}_{4}$, respectively, in order to prepare chlorinated $\mathrm{PHB}, \mathrm{PHB}-\mathrm{Cl}$, and chlorinated $\mathrm{PHO}, \mathrm{PHO}-\mathrm{Cl}$, with different chlorine contents. Then ATRP of vinyl monomers was initiated by using $\mathrm{PHA}-\mathrm{Cl}$ as macro initiators in order to obtain brushes containing PHAs (Scheme 33). 

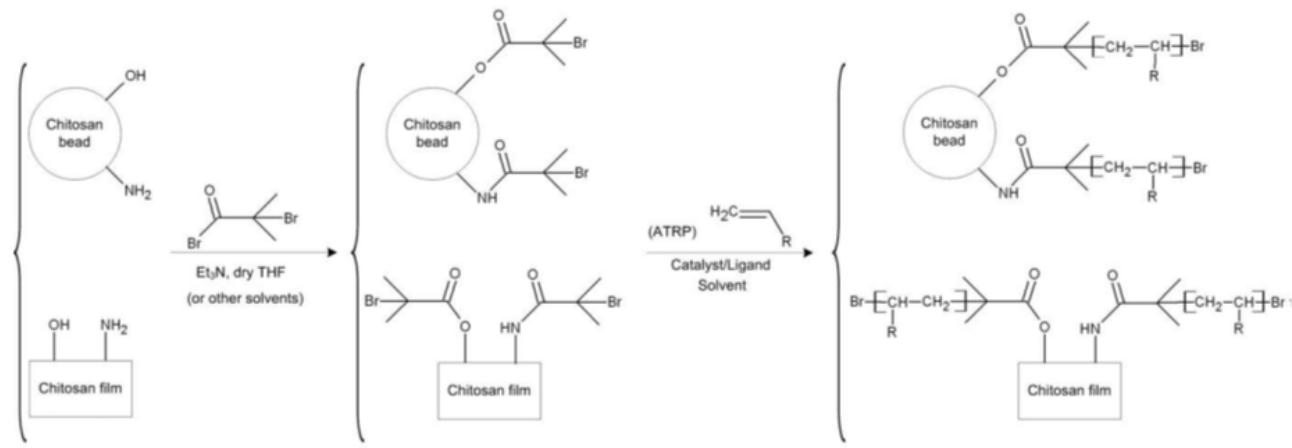

Scheme 32. Schematic presentation of the immobilization of surface initiator and polymerization of vinyl monomers via ATRP
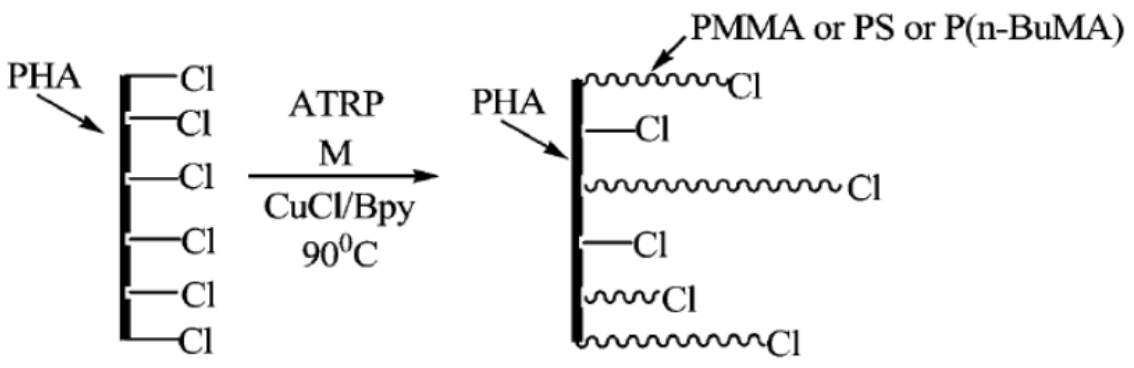

PHA-Cl

\section{PHA: $\mathrm{PHB}$ or $\mathrm{PHO}$ \\ M:MMA or S or n-BuMA}

Scheme 33. The synthesis of PHA-g-PMMA, PHA-g-PS, PHA-g-PBMA brush type graft copolymers via ATRP

Recently many studies on the synthesis of graft copolymers via ATRP in the literature have been also reported. Some of them are listed in Table 5.

\section{Block and graft copolymerzation by combined techniques}

In some cases, different controlled polymerization systems are combined to produce block and graft copolymers (see Table 6).

$\mathrm{Lu}$ et al reported the synthesis of block and graft copolymers of $\beta$-pinene and styrene by combination of living cationic polymerization and atom transfer radical polymerization methods (Scheme 34) [105].

Block copolymer synthesis via a combination of ATRP and RAFT using click chemistry was reported by Webster and co-workers (Scheme 35) [106]. 


\begin{tabular}{|l|l|l|}
\hline $1^{\text {st }}$ Segment & 2nd Segment & Ref. \\
\hline Chitosan & P(OEGMA) & {$[96]$} \\
Cellulose & PMMA & {$[97]$} \\
Cellulose & PS & {$[97]$} \\
Si/PGMA & PS & {$[98]$} \\
PBIEM-I & PMAIpGlc & {$[99]$} \\
MWNTs & PMAIpGlc & {$[100]$} \\
PVDF & PMAGlc & {$[101]$} \\
Si & PMMA & {$[102]$} \\
Si & PHEMA & {$[103]$} \\
Si & PDMAEMA & {$[103]$} \\
AuNPs & PHEMA & {$[104]$} \\
\hline
\end{tabular}

Poly(oligoethylene glycol methacrylate) (POEGMA), poly(glycidyl methacrylate) deposited on silicon wafer (Si/PGMA), poly(3-O-methacryloyl-1,2:5,6-di-O-isopropylidene-d-glucofuranose) (PMAIpGlc), poly(2-(2bromoisobutyryloxy)ethyl methacrylate) (PBIEM-I), poly(vinylidene fluoride) (PVDF), poly(3-O-methacryloyl-Dglucofuranose) (PMAIpGlc), silicon substrate (Si), Polymethylmethacrylate (PMMA), polystyrene (PS), poly(2(dimethylamino)ethylmethacrylate) (PDMAEMA), poly (2-hydroxyethyl methacrylate) (PHEMA), multiwalled carbon nanotubes (MWNTs), golg nanoparticules (AuNPs).

Table 5. Graft copolymers prepared using ATRP

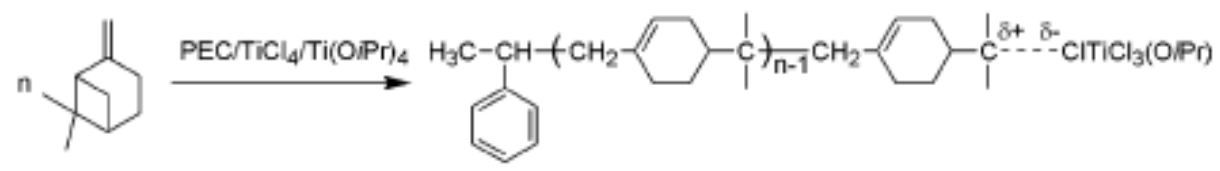

ß-pinene living polymer

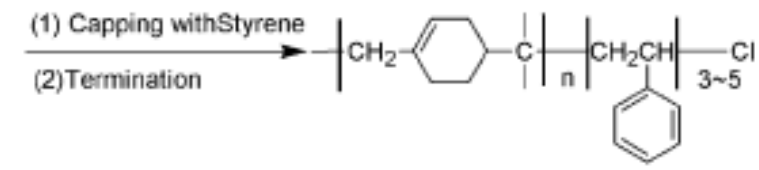

$\mathrm{P}(\beta-\mathrm{p})-\mathrm{St}-\mathrm{Cl}$

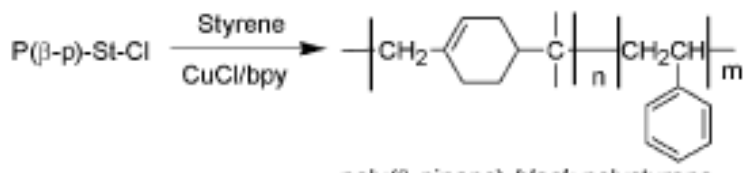

poly(b-pinene)-block-polystyrene

Scheme 34. Synthesis of poly( $\beta$-pinene)- $b$-polystyrene by combination of living cationic polymerization and atom transfer radical polymerization methods 


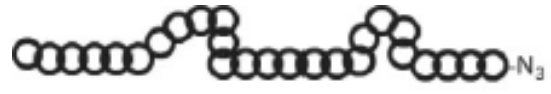

Polymer with azide group made by ATRP

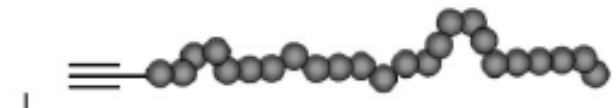

Polymer with propargyl group made by RAFT

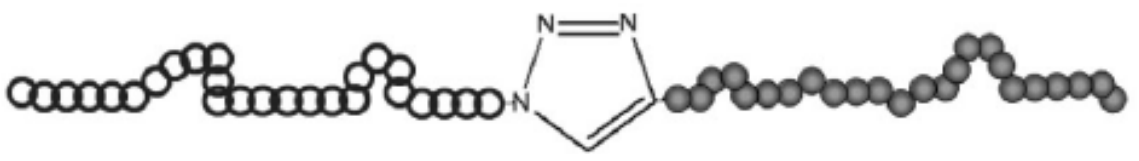

Scheme 35. Concept of combination of ATRP and RAFT using click chemistry.

\begin{tabular}{|l|l|l|}
\hline Combined polymerization techniques & Obtained composition & References \\
\hline Ring opening-ATRP & Dendrimer-like star block & {$[107]$} \\
ATRP-cationic polym. & AB type diblock & {$[108]$} \\
ATRP-macromonomer method & Graft & {$[109]$} \\
NMP-ATRP & Block-graft & {$[110]$} \\
NMP-RAFT & Graft & {$[111]$} \\
RAFT/MADIX-click Chemistry & Graft-block & {$[112]$} \\
NMP-iniferter technique & Graft & {$[113]$} \\
RAFT-click Chemistry & Block & {$[114]$} \\
Ring opening-NMP & Block & {$[115]$} \\
RAFT-ATRP-NMP & Bottle brush & {$[116]$} \\
\hline
\end{tabular}

Table 6. Some examples of polymers obtained by combination of different controlled polymerization mechanisms

\section{Conclusion}

The synthesis of block and graft copolymers can be achieved via different techniques such as free radical, anionic, cationic, coordination, coupling, step growth, ring opening, changing polymerization mechanism (active centers transformation reactions). CRP enables the synthesis of a wide range of (co)polymers with controlled molecular weight, narrow molecular weight distribution, and wide range of architectures (i.e., comb, star, dendritic, etc.), composition (i.e., random, periodic, graft, etc.) and functionalities at moderate experimental conditions.

\section{Author details}

Hülya Arslan

Bülent Ecevit University, Department of Chemistry, Zonguldak, Turkey

\section{Acknowledgement}

It is a pleasure to acknowledge for their contributions to my graduate students, at the Bülent Ecevit University. 


\section{References}

[1] Lodge T.P (2003) Macromol. chem. phys. 204: 265-273.

[2] Ueda J, Kamigaito M, Sawamoto M (1998) Macromolecules 31(20): 6762-6768.

[3] Shinoda H, Miller P. J, Matyjaszewski K (2001) Macromolecules 34(10): 3186-3194.

[4] Noshay A and McGrath J. E (1977) Block Copolymers: Overview and Critical Survey, Academic Pres, New York .

[5] Ceresa R.J (ed.) (1976) Block and Graft Copolymerization, Vols. 1 and 2, Wiley, London.

[6] Hazer B (1989) Handbook of Polymer Science and Technology, Vol.1: Synthesis and Properties, Edited by Nicholas P. Cheremisinoff, by Marcel Dekker Inc. pp.133-176.

[7] Hazer B (1997) Handbook of Engineering Polymeric Materials, Edited by Nicholas P. Cheremisinoff, by Marcel Dekker Inc. pp: 725-734.

[8] Yağcı Y and Mishra M.K (1996) Polymeric Materials Encyclopaedia, Vol. 1, Salamone J.(ed.), by CRC Press Inc. USA, pp. 789-796.

[9] Fradet A (1996) Polymeric Materials Encyclopaedia, Vol. 1, Salamone J.(ed.), by CRC Press Inc. USA, pp. 797-807.

[10] Mishra M. K and Yağcı Y (1996) Polymeric Materials Encyclopaedia, Vol. 1, Salamone J.(ed.), by CRC Press Inc. USA, pp. 808-814.

[11] Ueda M (1999) Prog. polym. sci. 24: 699-730.

[12] Bhattacharya A, Misra B. N (2004) Prog. polym. sci. 29: 767-814.

[13] Arslan H, Yesilyurt N, Hazer B (2007) Journal of applied polymer science 106: 17421750.

[14] Arslan H, Yesilyurt N, Hazer B (2008) Macromol. symp. 269: 23-33.

[15] Cai Y, Hartenstein M and Müller A.H.E (2004) Macromolecules 37: 7484-7490.

[16] Zhang M, Breiner T, Mori H, Müller A.H.E (2003) Polymer 44: 1449-1458.

[17] Sarbu T, Lin K, Spanswick J, Gil R R, Siegwart D.J and Matyjaszewski K (2004) Macromolecules 37: 9694-9700.

[18] Chung I.S and Matyjaszewski K (2003) Macromolecules 36: 2995-2998.

[19] Shen Y, Zhu S, Zeng F. and Pelton R (2000) Macromolecules 33: 5399-5404.

[20] Coessens V, Pintauer T, Matyjaszewski K (2001) Progress in polymer science 26: 337-377.

[21] Yuan X, Lu J, Xu Q, Wang L (2005) Polymer 46: 9186-9191.

[22] Muthukrishnan S, Jutz G, Andre X, Mori H and Müller A.H.E (2005) Macromolecules 38: 9-18.

[23] Muthukrishnan S, Mori H and Müller A.H.E (2005) Macromolecules 38: 3108-3119.

[24] Ydens I, Degee P, Dubois P, Libiszowski J, Duda A, Penczek S (2003) Macromol. chem. phys. 204: 171-179.

[25] Beers K.L and Matyjaszewski K (2001) J. macromol. sci.-pure appl. chem. A38(7): 731-739.

[26] Zhang Z, Ying S, Zhang Q, Xu X (2001) J. polym. sci.: part A: polym. chem. 39: 2670-2676.

[27] Hawker C. J, Bosman A. W.and Harth E (2001) Chem. rev.101: 3661-3688.

[28] Nicolas J, Charleux B, Guernet O and Magnet S (2005) Macromolecules 38: 9963-9973.

[29] Boyes S.G, Granville A. M, Baum M, Akgün B, Mirous B.K, Brittain W. J (2004) Surface science 570: 1-12.

[30] Lipscomb C. E and Mahanthappa M. K (2009) Macromolecules 42: 4571-4579. 
[31] Matyjaszewski K (2002) General Concepts and History of Living Radical Polymerization, In Handbook of Radical Polymerization; Matyjaszewski, K., Davis, T.P., eds. John Wiley and Sons, Inc.:Hoboken, pp 383-386.

[32] Matyjaszewski K, Spanswick J (2005) Controlled/living radical polymerization, Materials Today 8(3): 26-33.

[33] Patten T.E and Matyjaszewski K (1998) Adv. Mater. 10: 901-915.

[34] Bussels R (2004) (Multi)block copolymer synthesis via controlled radical polymerization in aqueous dispersions / by Raf Bussels, Eindhoven:Technische Universiteit Eindhoven, Proefschrift. - ISBN 90-386-2825-0,CIP-DATA LIBRARY TECHNISCHE UNIVERSITEIT EINDHOVEN.

[35] Müftüoğlu A. E, Taşdelen M. A, Yağc1 Y and Mishra M.K (2009 ) Handbook of Vinyl Polymers: Radical Polymerization, Process and Technology CRC Press Taylor \&Francis Group, New York, Ch11: pp. 307-344.

[36] Bomsan A. W, Frechet J. M. J, Hawker C. J (2001) Polym. mater. sci. eng., 84: 376-??

[37] Choi H, Park M, Lee S, Hong S.C (2008) European polymer journal 44: 3087-3095.

[38] Britze A, Jacob J, Choudhary V, Moellmann V, Grundmeier G, Luftmann H, Kuckling D (2010) Polymer 51: 5294-5303.

[39] Groison E, Brusseau S, D'Agosto F, Magnet S, Inoubli R, Couvreur L and Charleux B (2012) ACS Macroletters 1: 47-51.

[40] Ruehl J, Nilsen A, Born S, Thoniyot P, Xu L, Chen S, Braslau R (2007) Polymer 48: 25642571.

[41] Cheng S, Beyer F.L, Mather B.D, Moore R.B and Long T.E (2011) Macromolecules 44: 6509-6517.

[42] Narumi A, Matsuda T, Kaga H, Satoh T, Kakuchi T (2002) Polymer 43: 4835-4840.

[43] Thakur S, Cohen N. A, Tillman E.S (2008) Polymer 49: 1483-4189.

[44] Detrembleur C, Debuigne A, Jerome C, Phan T. N. T, Bertin D and Gigmes D (2009) Macromolecules 42: 8604-8607.

[45] Maric M, Lessard B.H, Consolante V, Ling E. J. Y (2011) Reactive\&Functional Polymers 71: 1137-1147.

[46] Beaudoin E, Dufils P. E, Gigmes D, Marque S, Petit C, Tordo P, Bertin D (2006) Polymer 47: 98-106.

[47] Okamura H, Takatori Y, Tsunooka M, Shirai M (2002) Polymer 43: 3155-3162.

[48] Yan J, Ji W, Chen E, Li Z, Liang D (2008) Macromolecules 41: 4908-4913.

[49] Pearson S, Allen N, Stenzel M. H (2009) J.of polym. sci.:part A:polymer chem., 47:1706-1723.

[50] Nguyen M. N, Bressy C, Margaillan A (2009) Polymer 50: 3086-3094.

[51] Sordi M. L. T, Riegel I. C, Ceschi M. A, Müller A. H. E, Petzhold C. L (2010) Eur. polym. j. 46: 336-344.

[52] An Z. S, Shi Q. H, Tang W, Tsung C. K, Hawker C. J, Stucky G. D (2007) J. am. chem. soc. 129: 14493-14499.

[53] Guan C, Luo Z, Qiu J, Tang P (2010) Eur. polym. j. 46: 1582-1593.

[54] Zheng L, Chai Y, Liu Y, Zhang P (2011) e-Polymers 39: 1-8.

[55] You Y, Zhou Q, Manickam D. S, Wan L, Mao G and Qupicky D (2007) Macromolecules 40: 8617-8624. 
[56] Baum M and Brittain W J (2002) Macromolecules 35: 610-615.

[57] Albertin L, Stenzel M. H, Barner-Kowallik C, Foster L. J. R and Davis T. P (2005) Macromolecules 38: 9075-9084.

[58] Öztürk Z, Komber H, Gram S, Schmaljohann D, Müler A. H. E, Voit B (2007) Macromolecular chemistry and physics 208:1035-1049.

[59] Liu L, Wu C, Zhang J, Zhang M, Liu Y, Wang X, Fu G (2008) J. polym. sci.: part A: polymer chemistry 46: 3294-3305.

[60] Smith A. E, Xu X, Kirkland-York S. E, Savin D. A and McCormick C. L, Macromolecules (2010) 43: 1210-1217.

[61] Zhang L, Bernard J, Davis T. P, Barner-Kowallik C, Stenzel M. H (2008) Macromolecular Rapid Communications 29: 123-129.

[62] Lipscomb C. E and Mahanthappa M. K (2009) Macromolecules 42: 4571-4579.

[63] Albertin L, Stenzel M, Barner-Kowallik C, Foster L. J. R and Davis T. P (2004) Macromolecules 37:7530-7537.

[64] Can A, Altuntas E, Hoogenboom R, Schubert U. S (2010) Eur. polym. j. 46: 1932-1939.

[65] Motala-Timol S, Jhurry D (2007) Eur. polym. j. 43: 3042-3049.

[66] Huang W, Kim J, Baker G. L and Bruening M. L (2003) Nanotechnology 14: 1075-1080.

[67] Shipp D. A, Wang J and Matyjaszewski K (1998) Macromolecules 31: 8005-8008.

[68] Nakagawa Y, Miller P. J and Matyjaszewski K (1998) Polymer 39(21): 5163-5170.

[69] Ohno K, Tsujii Y, Fukuda T (1998) J. of polym. sci.: part A: polym. chem. 36: 2473-2481.

[70] Cassebras M, Pascual S, Polton A, Tardi M, Vairon J (1999) Macromol. rapid commun. 20: 261-264.

[71] Wang X, Luo N, Ying S, Liu Q (2000) Eur. polym. j. 36: 149-156.

[72] Lee S. B, Russell A. J and Matyjaszewski K (2003) Biomacromolecules 4: 1386-1393.

[73] Strissel C, Matyjaszewski K, Nuyken O (2003) Macromol. chem. phys. 204: 1169-1177.

[74] Licciardi M, Tang Y, Billingham N. C and Armes S. P (2005) Biomacromolecules 6: 10851096.

[75] Xu C, Wu T, Batteas J. D, Drain C. M, Beers K. L, Fasolka M. J (2006) Applied surface science 252: 2529-2534.

[76] Paris R, Luis de la Fuente J (2008) Eur. polym. j. 44: 1403-1413.

[77] Oikonomou E. K, Pefkianakis E. K, Bokias G, Kallitsis J. K (2008) Eur. polym. j. 44: 18571864.

[78] Suriano F, Coulembier O, Degee P, Dubois P (2008) J. of polym. sci.: part A: polym. chem. 46: 3662-3672.

[79] Pasparakis G and Alexander C (2008) Angew. chem. int. ed. 47: 4847-4850.

[80] Advincula R. C, Brittain W. J, Caster K. C, Ruhe J (2004) Polymer Brushes: Synthesis, Characterization, Applications (John Wiley \&Sons, New York).

[81] Hua D, Deng W, Tang J, Cheng J, Zhu X (2008) International journal of biological macromolecules, 43: 43-47.

[82] Jiang J, Hua D, Jiang J, Tang J, Zhu X (2010) Carbohydrate polymers 81: 358-364.

[83] Jaymand M (2011) Polymer 52: 4760-4769.

[84] Chen Y, Ying L, Yu W, Kang E.T and Neoh K.G (2003) Macromolecules 36: 9451-9457.

[85] Ying L, Yu W.H, Kang E.T and Neoh K.G (2004) Langmuir 20: 6032-6040. 
[86] Roy D, Guthrie J.T and Perrier S (2005) Macromolecules 38: 10363-10372.

[87] Stenzel M.H, Zhang L, Huck W.T.S (2006) Macromol. rapid commun. 27: 1121-1126.

[88] Hua D, Tang J, Cheng J, Deng W, Zhu X (2008) Carbohydrate polymers 73: 98-104.

[89] Morimoto N, Qiu X, Winnik F.M and Akiyoshi K (2008) Macromolecules 41: 5985-5987.

[90] Mespouille L, Nederberg F, Hedrick J.L and Dubois P (2009) Macromolecules 42: 63196321.

[91] Li J, Yi L, Lin H, Hou R (2011) Journal of polymer science part A: polymer chemistry 49: 1483-1493.

[92] Tahlawy K and Hudson S. M (2003) Journal of applied polymer science 89: 901-912.

[93] Li N, Bai R and Liu C (2005) Langmuir 21: 11780-11787.

[94] Arslan H, Yeşilyurt N, Hazer B (2007) J. of app. polym. sci. 106: 1742-1750.

[95] Arslan H, Yeşilyurt N, Hazer B (2008) Macromol. symp. 269: 23-33.

[96] Munro N. H, Hanton L. R, Moratti S. C, Robinson B. H (2009) Carbohydrate polymers 77: 496-505.

[97] Meng T, Gao X, Zhang J, Yuan J, Zhang Y, He J (2009) Polymer 50: 447-454.

[98] Liu Y, Klep V, Zdyrko B and Luzinov I (2004) Langmuir 20: 6710-6718.

[99] Muthukrishnan S, Zhang M, Burkhardt M, Drechsler M, Mori H and Müler A. H. E (2005) Macromolecules 38: 7926-7934.

[100] Gao C, Muthukrishnan S, Li W, Yuan J, Xu Y and Müler A. H. E (2007) Macromolecules 40: 1803-1815.

[101] Wang J, Xu Y, Xu H, Zhang F, Qian Y, Zhu B (2008) J. of app. polym. sci. 109: 2914-2923.

[102] Wang Y, Pei X, He X, Lei Z (2005) Eur. polym. j. 41: 737-741

[103] Xu F. J, Cai Q. J, Kang E. T and Neoh K. G (2005) Langmuir 21: 3221-3225.

[104] Bach L. G, Islam Md. R, Jeong Y. T, Gal Y. S, Lim K. T (2012) Applied surface science 258: 2816-2822.

[105] Lu J, Liang H, Li A, Cheng Q (2004) European polymer journal 40: 397-402.

[106] Nasrullah M. J, Vora A, Webster D. C (2011) Macromol. chem. phys. 212: 539-549.

[107] Hedrick J. L, Trollsas M, Hawker C. J, Atthoff B, Claesson H, Heise A and Miller R. D (1998) Macromolecules 31: 8691-8705.

[108] Düz A. B, Yağc1 Y (1999) European polymer journal 35: 2031-2038.

[109] Shinoda H, Miller P. J and Matyjaszewski K (2001) Macromolecules 34: 3186-3194.

[110] Tasdelen M. A, Yagci Y, Demirel A. L, Biedron T, Kubisa P (2007) Polymer bulletin 58: 653-663.

[111] Wang S, Cheng Z, Zhu J, Zhang Z, Zhu X (2007) Journal of polymer science: part A: polymer chemistry 45: 5318-5328.

[112] Quemener D, Le Hellaye M, Bissett C, Davis T. P, Barner-Kowallik C, Stenzel M. H (2008) Journal of polymer science: part A: polymer chemistry 46: 155-173.

[113] Gromadzki D, Makuska R, Netopilik M, Holler P, Lokaj J, Janata M, Stepanek P (2008) European polymer journal 44: 59-71.

[114] Xue X, Zhu J, Zhang Z, Cheng Z, Tu Y, Zhu X (2010) Polymer 51: 3083-3090.

[115] Habraken G. J. M, Peeters M, Thornton P. D, Koning C. E and Heise A (2011) Biomacromolecules 12: 3761-3769.

[116] Zehm D, Laschewsky A, Liang H and Rabe J. P (2011) Macromolecules 44: 9635-9641. 